\title{
Design Chart of a footing located on a Crest of the Unsaturated Soil slopes
}

\author{
${ }^{1}$ Suhail A. A. Khattab, ${ }^{2 B a y e r ~ J . ~ A l-S u l a i f a n i e, ~}{ }^{3}$ Rabi' A. Mohammed \\ 1,2Civil Engineering Department, University of Mosul, Mosul, Iraq \\ ${ }^{3}$ Civil Engineering Department, University of Mosul, Mosul, Iraq
}

\begin{abstract}
A parametric study points out the effect of various influential parameters on the stability of the unsaturated clayey and alluvial soil slopes using finite element computer programs of GEOSLOPE. The rainfall intensity and duration is considered as one of the studied parameters, three intensity values are selected (10, 24 and 50) mm/day (with different duration 10, 20, 30, 40, 50 and 60) day. Phreatic line level is the second parameter studied, at 2, 4, and 6m from surface. In addition to that, footing width is studied as the third parameter. Consequently, three different widths are selected $(1,2$, and $3 \mathrm{~m})$. Slope angle is also selected as the fourth parameters; four different angles are selected $(31,45,63$ and 81$)$ degree. As a result, a chart for routine design is obtained.
\end{abstract}

KEYWORDS: Design Chart, footing, Unsaturated Soil, slope.

\section{Introduction}

Embankments and slopes fail each year in many spots around the world. In fact, such slope failure usually poses a serious threat for both lives and properties as well. These slope failures might take place because of human-induced factors such as loading of the slope, cutting away of the toe for construction purposes or because of environmental factors. Several possible factors in nature can result in the instability of the soil slope such as rainfall infiltration, earthquakes, etc. This process of rainfall infiltration into a soil slope has been always considered as a difficult problem because of several factors such as, soil initial moisture condition soil permeability and the retention of water by the soil. Whenever the unsaturated soils are dealt with, the problem will become more complicated because the hydraulic properties of the soils are strongly non-linear functions (Zou et al., 2001; Lee et al., 2011). In the season

Academic Journal of Nawroz University (AJNU)

Volume 8, No 4 (2019).

Regular research paper : Published 6 Nov 2019

Corresponding author's e-mail : Suhail.a@gmail.com

Copyright (C2018 1Suhail A. A. Khattab, 2Bayer J. Al-Sulaifanie,

3Rabi' A. Mohammed.This is an open access article distributed under the Creative Commons Attribution License. of rainfall; the water infiltrates through the upper soil layer and then, enters the lower soil layer only in case when there is a decrease of the matric suction at the surface of the lower layer to a limit which is near the water entry point (Stormont and Anderson, 1999). The failure of slopes is due to the loss of matric suction during rainwater infiltration. Thus, it causes an increase in pore water pressure and reduction in soil shear strength and subsequently triggers the slope failure (Fredlund and Rahardjo, 1993; Chen et al., 2004; Travis et al., 2010). As a result, the analysis of suction distribution in the vadoze zone of unsaturated soil is essential for the study of slope failure in soil (Kassim et al. 2012).

The Finite Element Method (FEM) has been developed into a key, indispensable technology in the modelling and simulation of advanced engineering systems, like stress analysis, thermal analysis, fluid flow analysis, piezoelectric analysis, and many others. In fact, the FEM is a numerical method seeking an approximated solution of the distribution of field variables in the problem domain that is analytically difficult to obtain. This is achieved by dividing the problem domain into several 
elements. The triangular and quadrilateral shapes of the elements are commonly used for two-dimensional problems. A continuous function of an unknown field variable is approximated by using piecewise linear functions in each sub-domain called an element formed by nodes. Consequently, the unknown is the discrete values of the field variable at the nodes. Then, the proper principles are followed in order to establish the equations for the elements, and then the elements will be 'tied' to one another. Such process will lead to a set of linear algebraic simultaneous equations for the whole system that may be solved without difficulty to attain the required field variable (Liu and Quek, 2003).

\section{FINITE ELEMENT SIMULATION OF THE}

\section{PARAMETRIC STUDY.}

Two different types of soil, namely, clay soil designated as (A) and alluvial soil designated as (B) were used in this study. The physical properties of these types of soil are shown in Table (1), and they were classified as $(\mathrm{CH}$ and ML) respectively, according to unified soil classification system. Figure (1) shows the geometry, boundary conditions and the finite element mesh. The dimensions of the studied slope are $8 \mathrm{~m}$ in height and 20 $m$ in width, the form of the mesh elements are chosen to be 'Quads and triangles'. A typical mesh with global element size $1 \mathrm{~m}$ and refined element are used within the influence zone of the loaded footing by comprised elements size less than $0.25 \mathrm{~m}$. The form of the structure beam element is used to the simulation of the footing with a full fixity $\left(\mathrm{U}_{\mathrm{x}}=\mathrm{U}_{\mathrm{y}}=0\right)$, the properties of the footing are identified in table (2).

\subsection{Effect of rainfall on the stability of the slope}

Three cases of rainfall intensity have been taken into account namely: (10, 24 and 50) mm/day (with different durations: 10, 20, 30, 40, 50 and 60) days are conducted for the soil slopes (A and B). In Figure (2), we could find the variation of the pore water pressure during rain
TABLE 1

Properties of Soils

\begin{tabular}{lcc}
\hline \hline \multicolumn{1}{c}{ Description } & Soil (A) & Soil (B) \\
\hline Liquid limit, L.L \% & 57 & N.P. \\
Plastic limit, PL \% & 30 & N.P. \\
Plasticity index, PI \% & 27 & N.P. \\
Specific gravity, Gs & 2.754 & 2.65 \\
\% Sand & 10 & 27 \\
$\%$ Silt & 62 & 67 \\
$\%$ Clay & 22 & 6 \\
Dry unit weight, $(\gamma d) \mathrm{kN} / \mathrm{m} 3$ & 15.6 & 16.2 \\
Optimum Moisture Content, $(\omega \%)$ & 22 & 16 \\
Angle of internal friction, $(\varnothing)$ & 24 & 37 \\
Cohesion, (c & 30 & 8 \\
Hydraulic conductivity, $(\mathrm{ks}) \mathrm{m} / \mathrm{hr}$ & $3.24 \mathrm{e}-4$ & $9 \mathrm{e}-4$ \\
\hline
\end{tabular}

infiltration at 1.5B. It is noticed that the higher decrease in the soil suction occurs at the first 20 days of rainfall and then approximately it remains constant until end of rainfall duration (i.e. 60 days). For soil slope (A), the pore pressure has been changed from $(-50) \mathrm{kPa}$ to (11.3, 15.9 and 81$) \mathrm{kPa}$ for intensity $(10,24$ and 50) $\mathrm{mm} /$ day respectively. As for soil (B), the pore pressure has been changed from (-10) $\mathrm{kPa}$ to $(4.3,13.2$ and 30.1) $\mathrm{kPa}$ for intensity $(10,24$ and 50) mm/day respectively. Figures ( 3 to 8 ) show the contour distribution for the pore water pressure with the depth during the rain period for all intensity cases. The increase in pore water pressure is due to the increase of water during rain water infiltration as previously mentioned.

TABLE 2 Input parameters for plates

\begin{tabular}{|l|c|l|l|}
\hline Plate parameter & Symbol & Values & Unit \\
\hline Thickness & $\mathrm{h}$ & 400 & $\mathrm{~mm}$ \\
\hline Width & $\mathrm{b}$ & 1000 & $\mathrm{~mm}$ \\
\hline $\begin{array}{l}\text { Modules of elasticity of } \\
\text { concrete }\end{array}$ & $\mathrm{E}$ & 24 & $\mathrm{GPa}$ \\
\hline
\end{tabular}




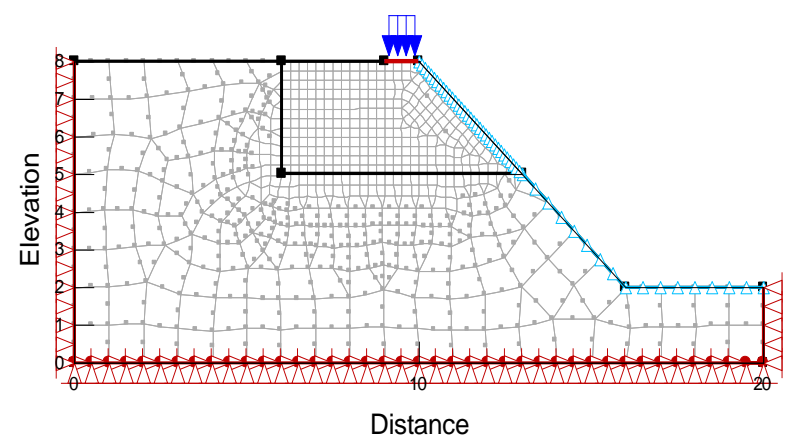

Fig. 1. Geometry and boundary conditions first parameter.

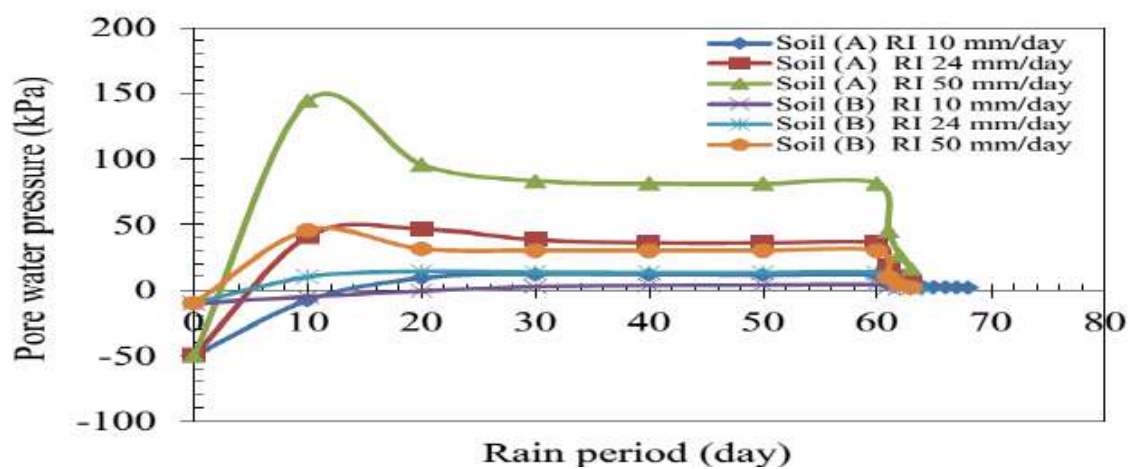

Fig. 2. Variations of pore water pressure during rain period at 1.5 B. 


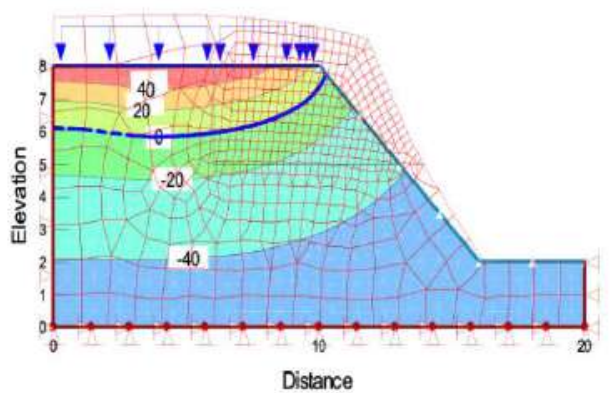

a) After (10) day of rain.

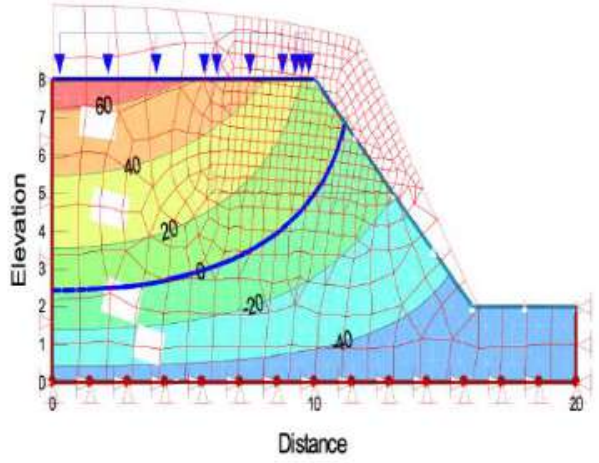

c) After (30) day of rain.

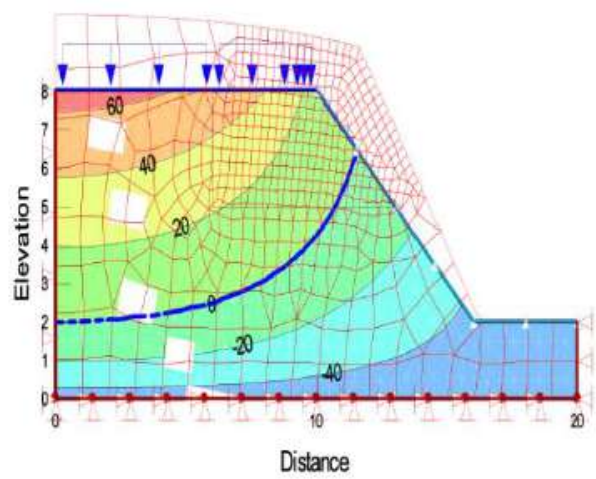

d) After (50) day of rain.

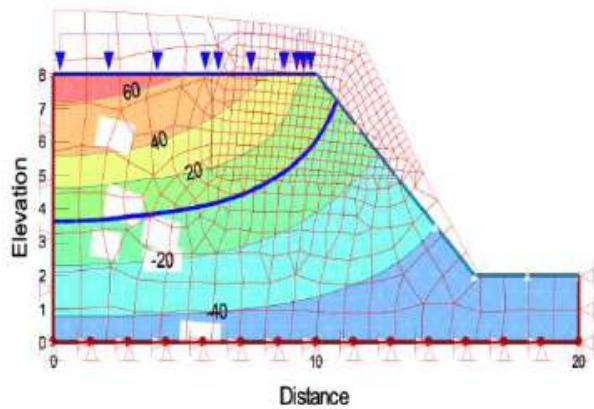

b) After (20) day of rain.

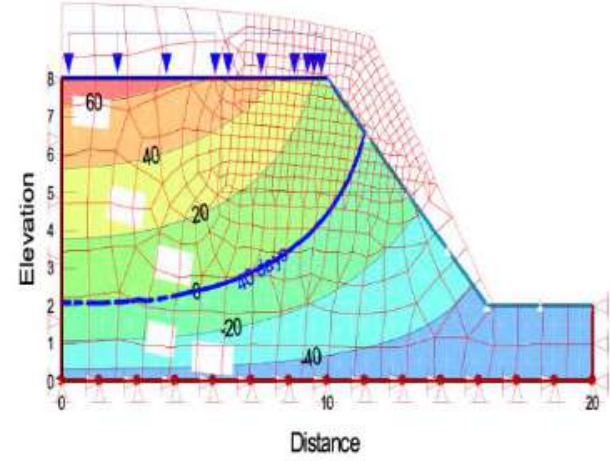

d) After (40) day of rain.

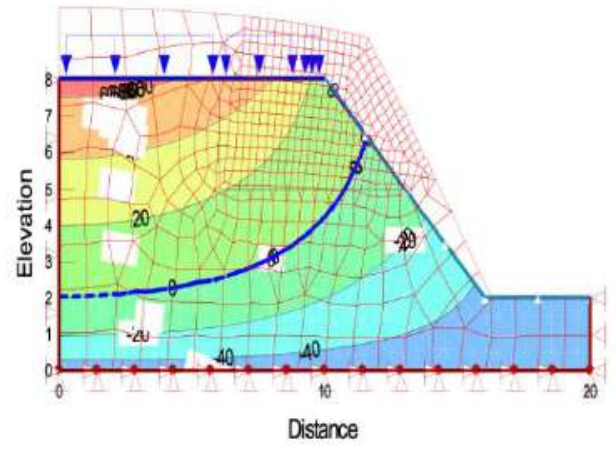

f) After (60) day of rain.

Fig. 3. Contours of pore water pressure and deformed shape due to rainfall intensity (10) $\mathrm{mm} /$ day for soil A. 


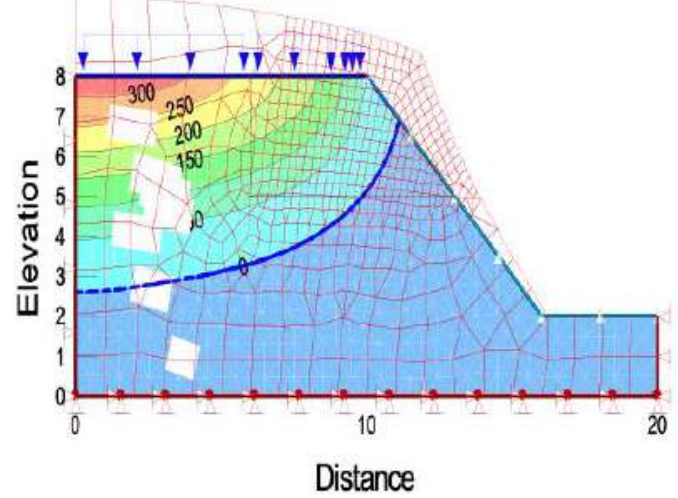

a) After (10) day of rain.

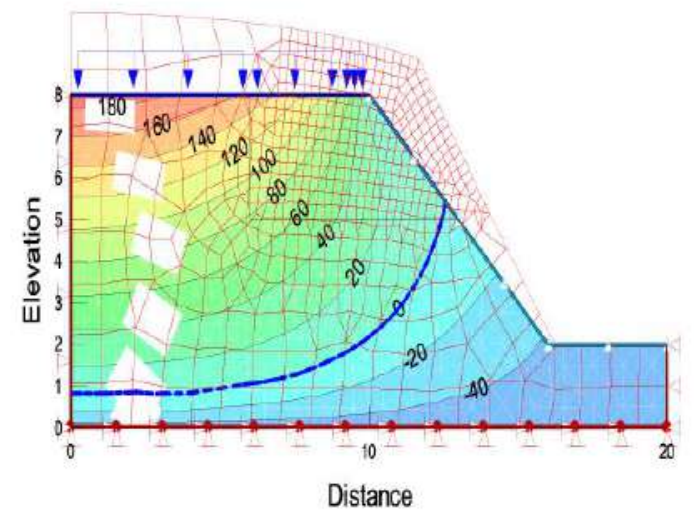

c) After (30) day of rain.

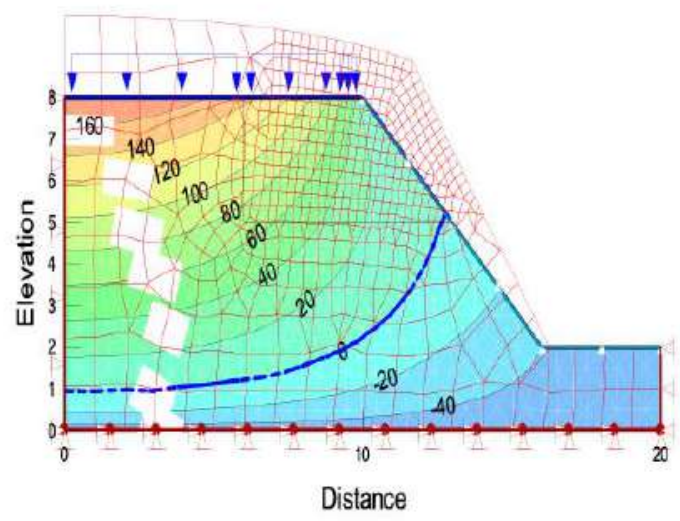

d) After (50) day of rain.

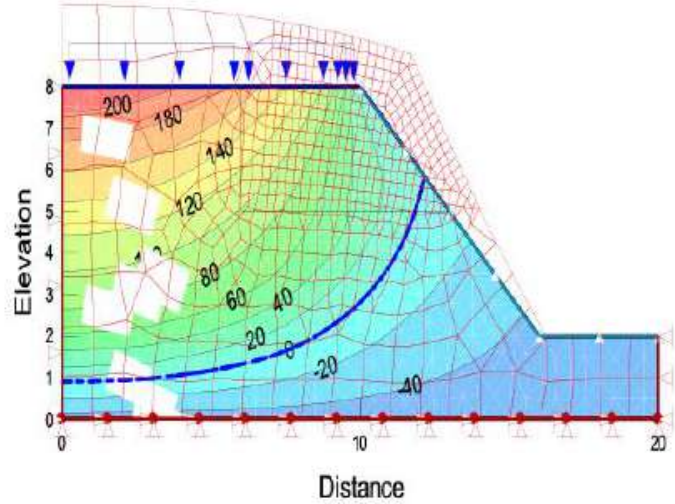

b) After (20) day of rain.

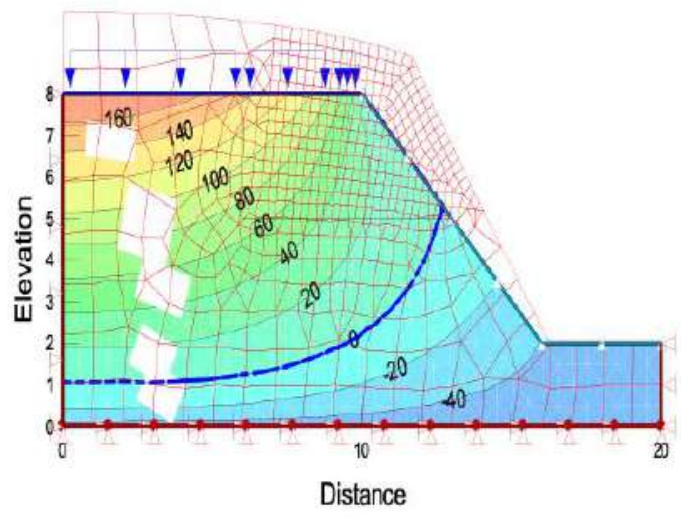

d) After (40) day of rain.

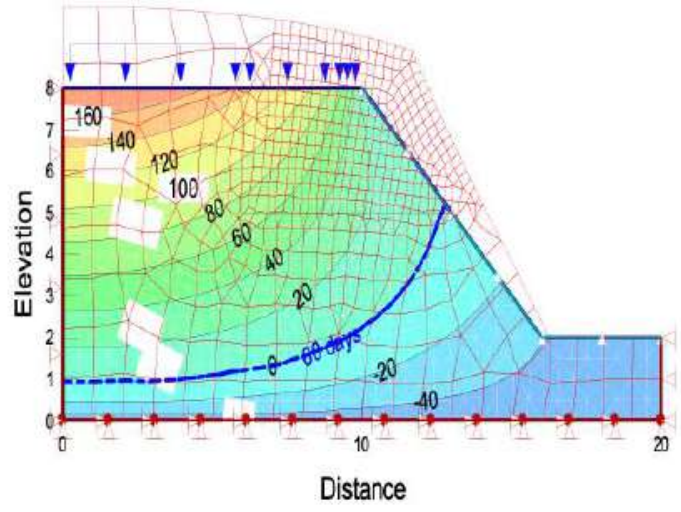

f) After (60) day of rain.

Fig. 4. Contours of pore water pressure and deformed shape due to rainfall intensity (24) $\mathrm{mm} /$ day for soil (A). 

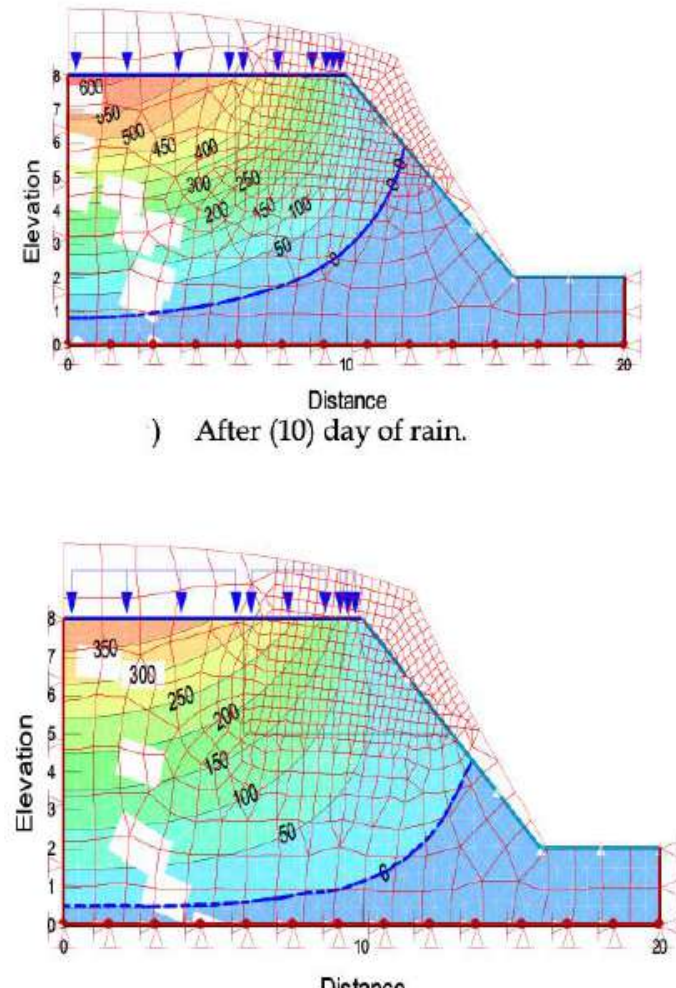

c) After (30) day of rain.

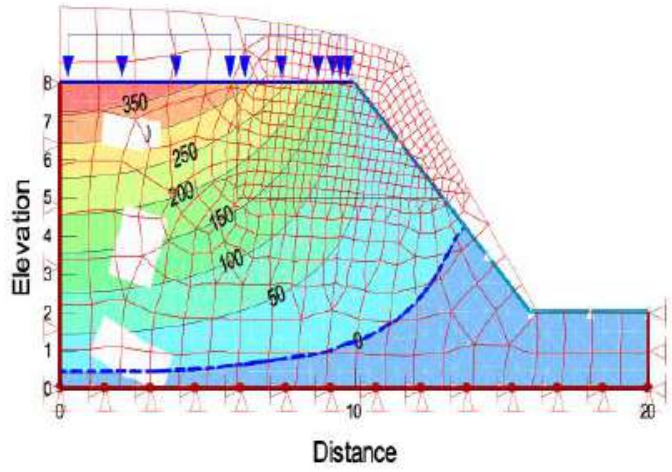

d) After (50) day of rain.

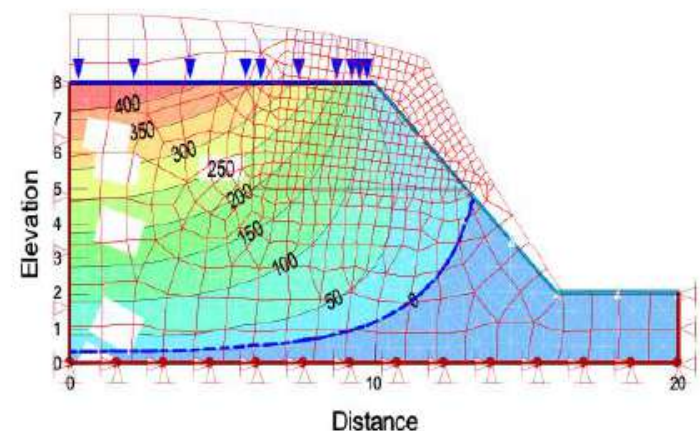

b) After (20) 'zy of rain.

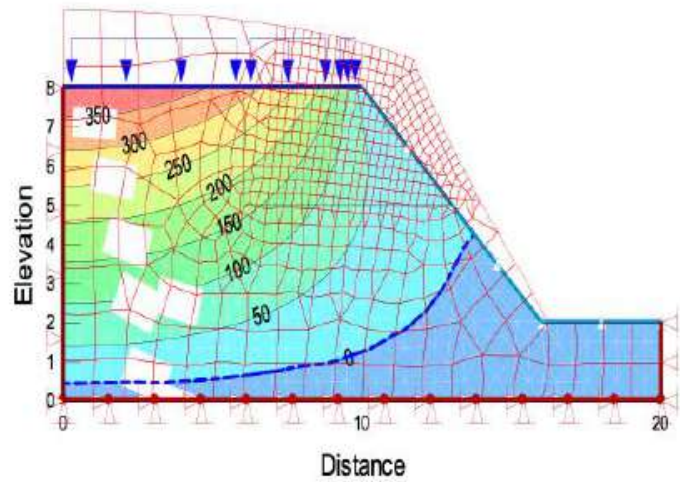

d) After (40) day of rain.

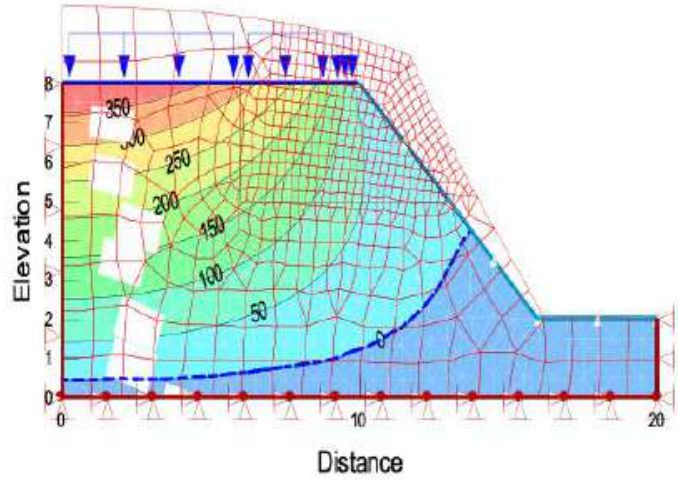

f) After (60) day of rain.

Fig. 5. Contours of pore water pressure and deformed shape due to rainfall intensity (50) $\mathrm{mm} /$ day for soil (A). 


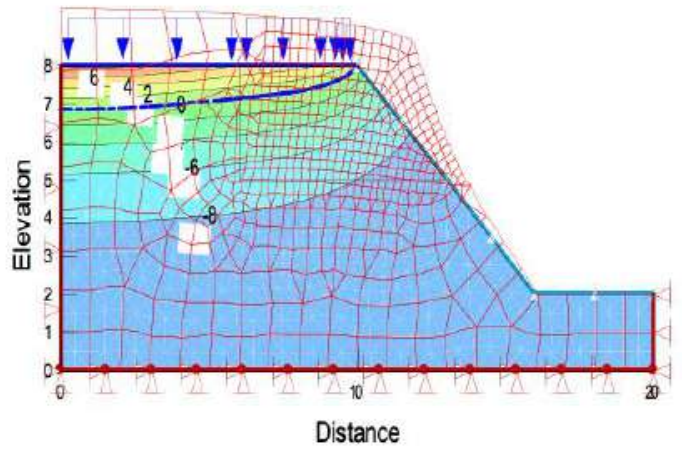

a) After (10) day of rain.

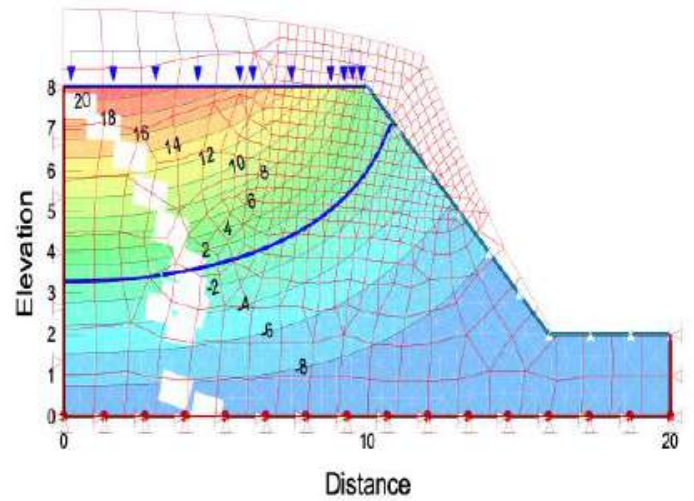

c) After (30) day of rain.

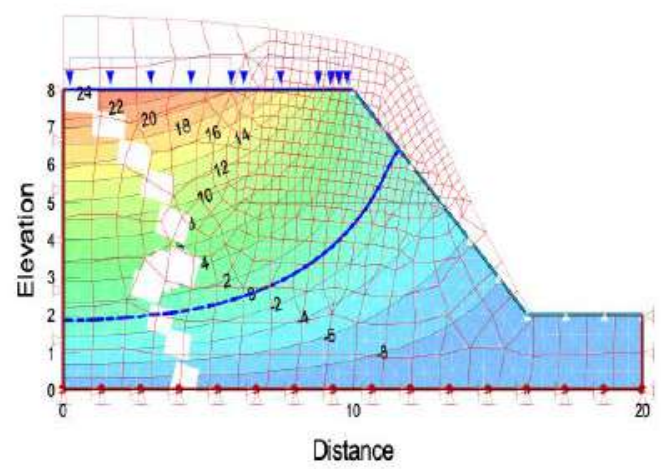

d) After (50) day of rain.

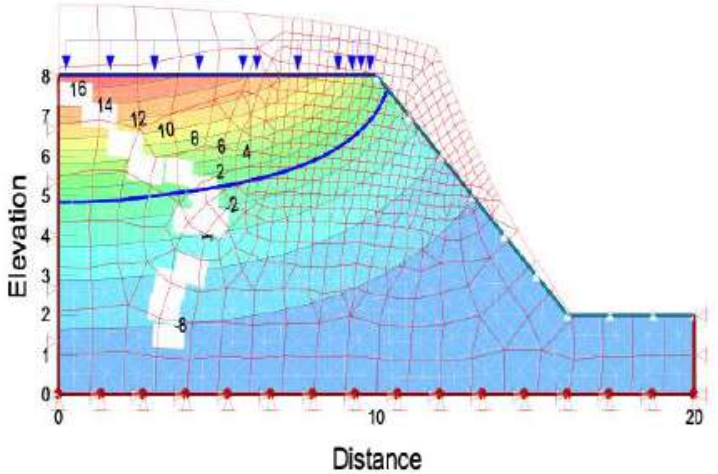

b) After (20) day of rain.

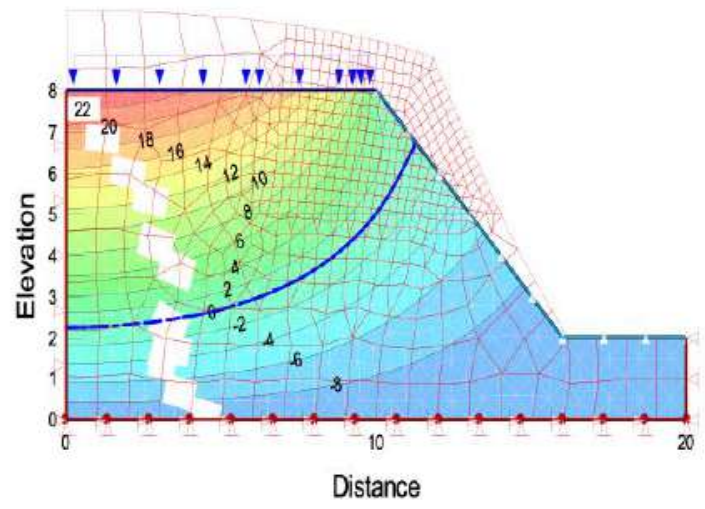

d) After (40) day of rain.

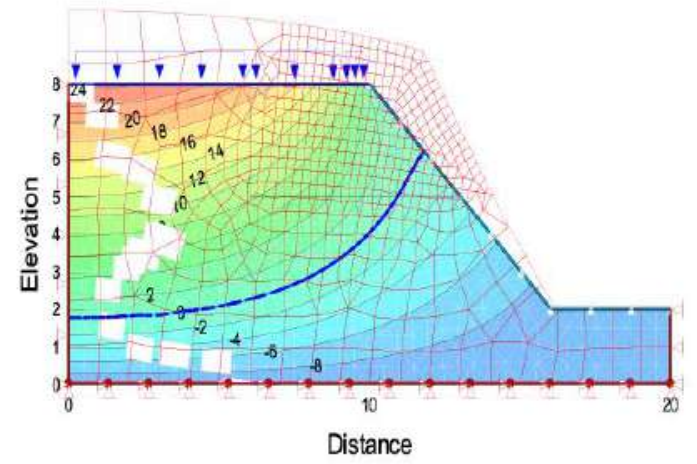

f) After (60) day of rain.

Fig. 6. Contours of pore water pressure and deformed shape due to rainfall intensity (10) $\mathrm{mm} /$ day for soil (B). 


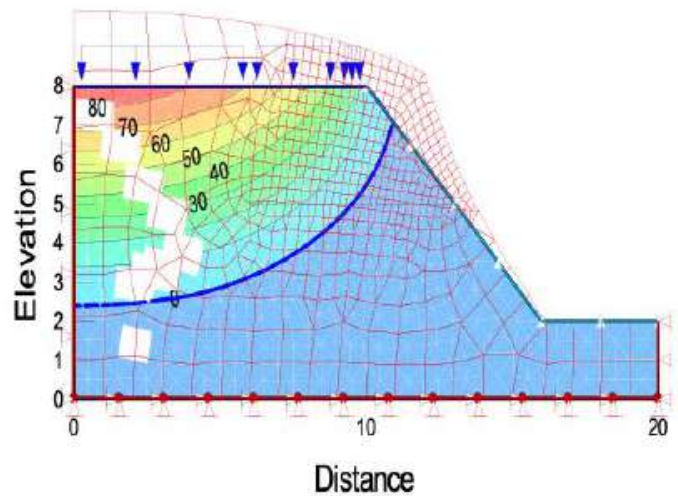

a) After (10) day of rain.

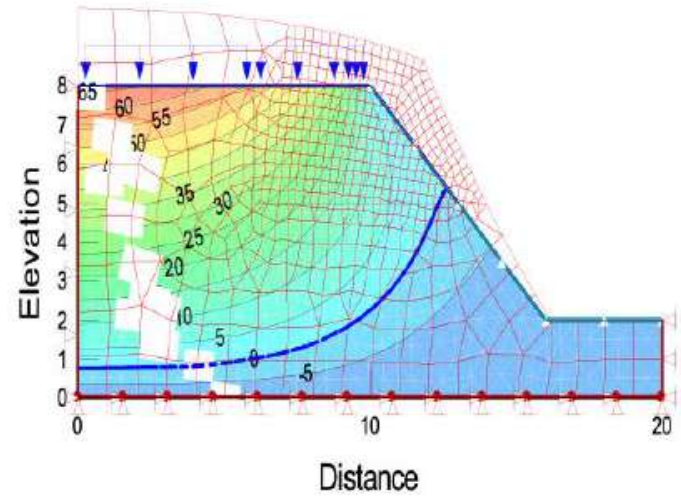

c) After (30) day of rain.

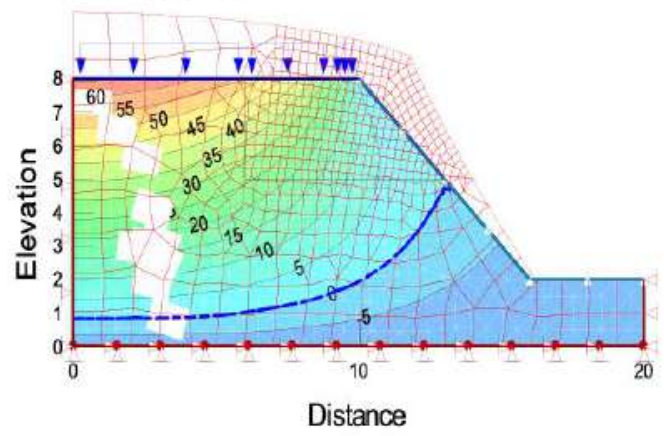

d) After (50) day of rain.

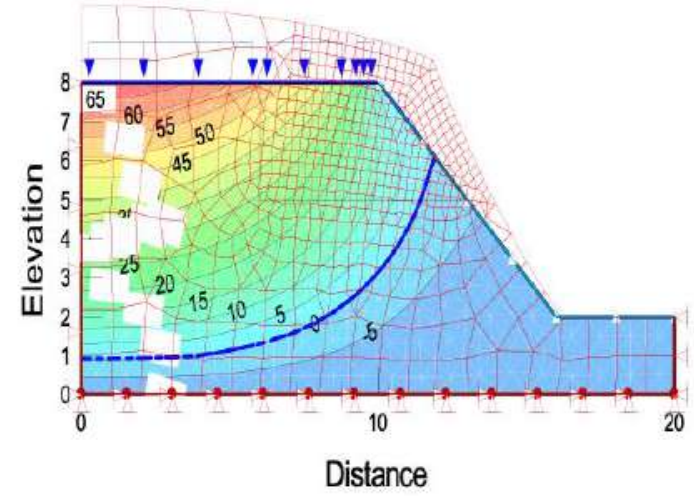

b) After (20) day of rain.

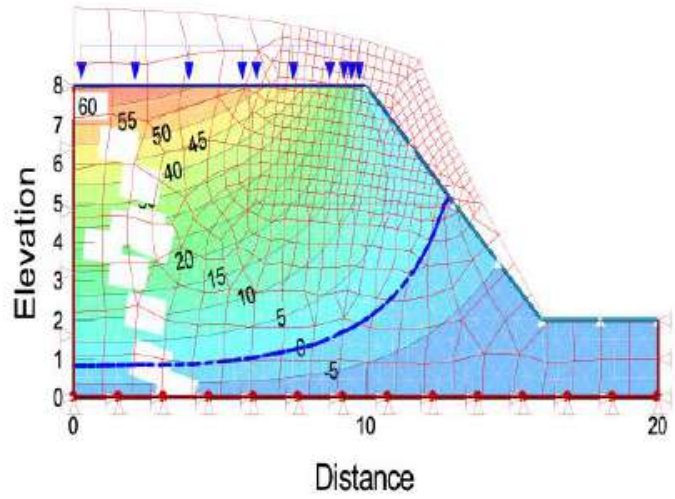

d) After (40) day of rain.

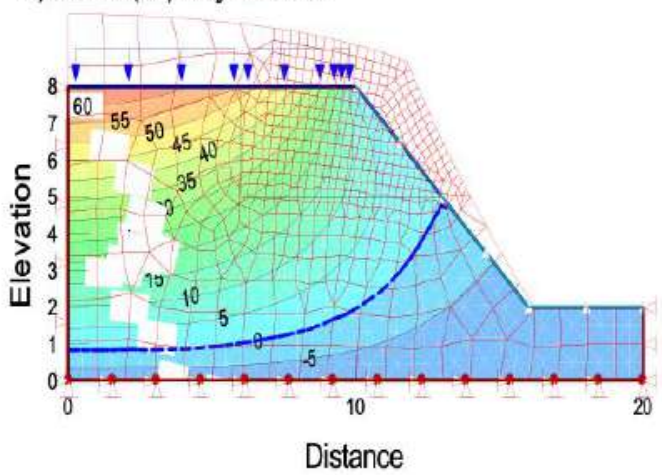

f) After (60) day of rain.

Fig. 7. Contours of pore water pressure and deformed shape due to rainfall intensity (24) $\mathrm{mm} /$ day for soil (B). 


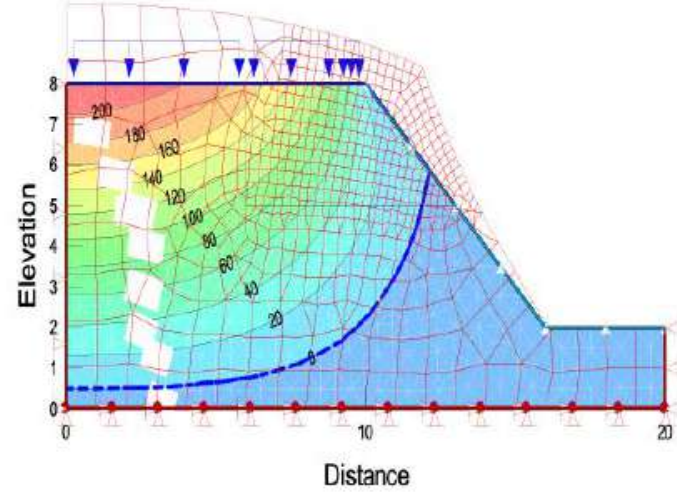

a) After (10) day of rain.

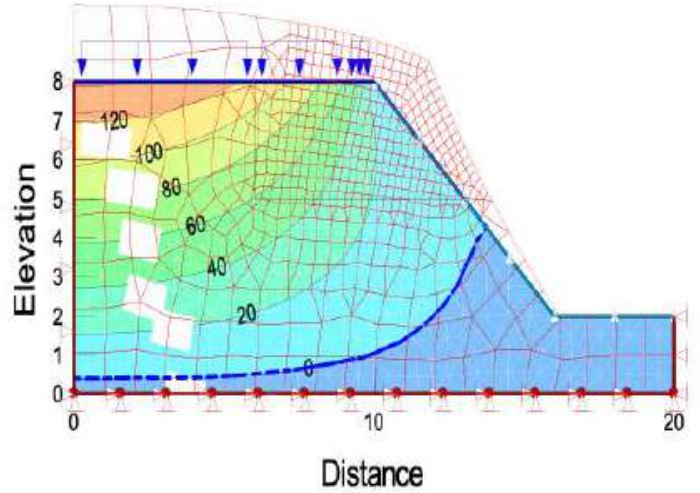

c) After (30) day of rain.

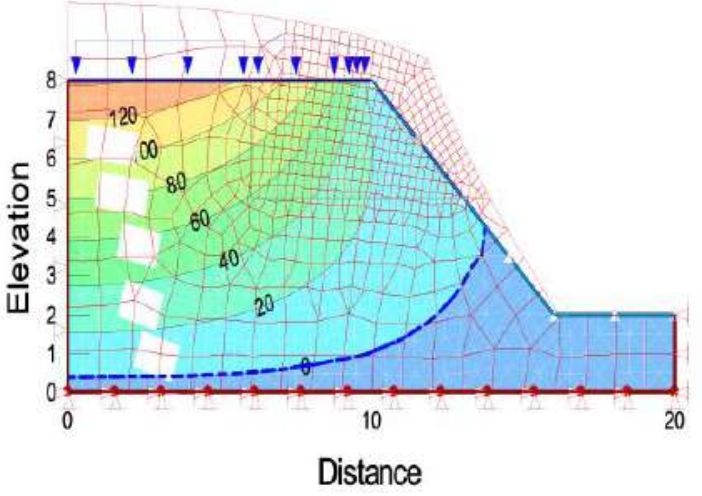

d) After (50) day of rain.

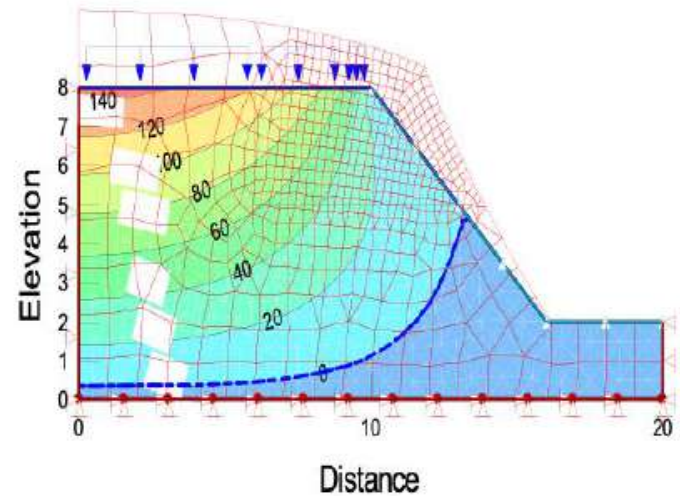

b) After (20) day of rain.

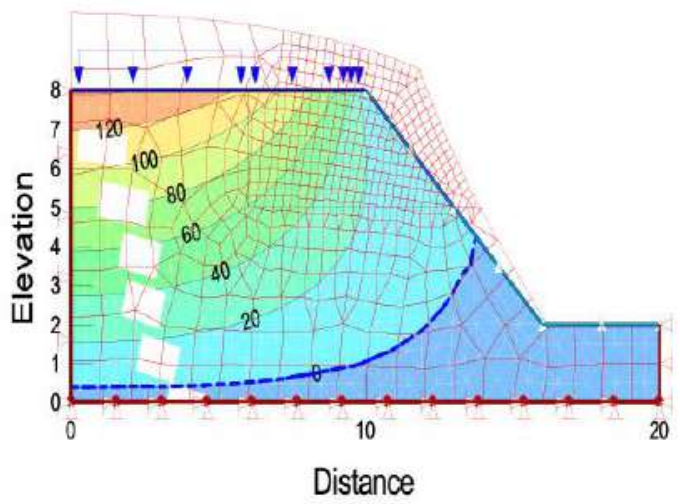

d) After (40) day of rain.

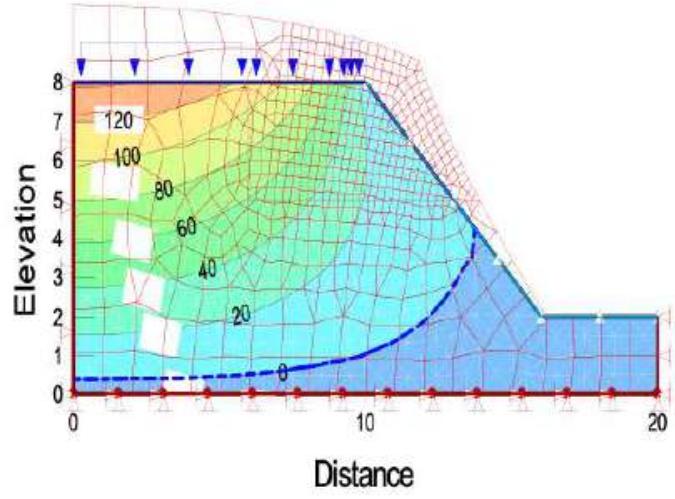

f) After (60) day of rain.

Fig. 8. Contours of pore water pressure and deformed shape due to rainfall intensity (50) $\mathrm{mm} /$ day for soil (B). 
Figures (9 and 10) show the changes in the factor of safety (FOS) with the rain period for different intensities $(10,24$ and 50) mm/day. For the first case, (i.e. rain intensity equal to10 $\mathrm{mm} /$ day); before any rainfall period, the factor of safety of the slopes (A and B) are (4.1 and 2.31) respectively which decrease to a values of (2.92 and 3.9) \% after 10 days of rainfall. On the other hand, this values decreases to (24.4 and 16.8) \% and reaches to (3.1 and 1.92) after 60 days of rainfall for soil slopes (A and B) respectively. For the second case, (i.e. rain intensity equal to $24 \mathrm{~mm} /$ day); the factor of safety which decreases to a value of (38.3 and $20 \%$ ) after 10 days of rainfall, while the factor of safety decreases to (48.1 and 32)\% and reaches to (2.12and 1.57) after 60 days of rainfall for soil slopes (A and B) respectively. For third case, (i.e. rain intensity equal to $50 \mathrm{~mm} /$ day); the factor of safety which decreases to a value of (58.7 and $100 \%$ ) after 10 days of rainfall, while the factor of safety decreases to (62.4 and $100 \%$ ) and reaches to (1.54 and 0)after 60 day of rainfall for soil slopes (A and B) respectively.

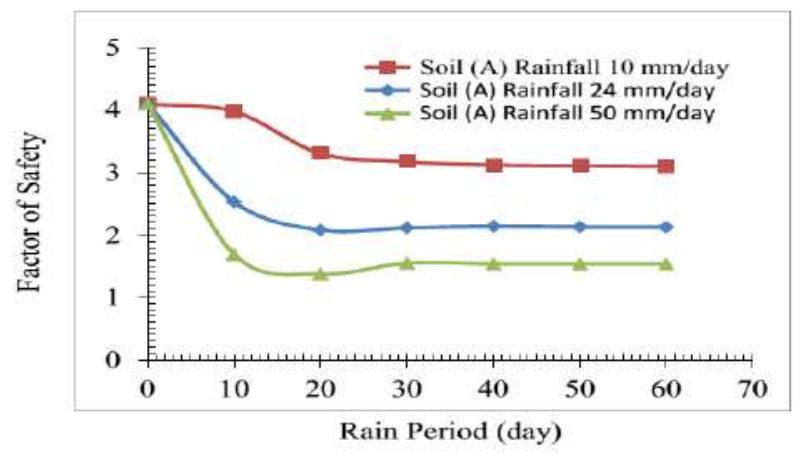

Fig. 9. Factor of safety with rain period for soil (A).

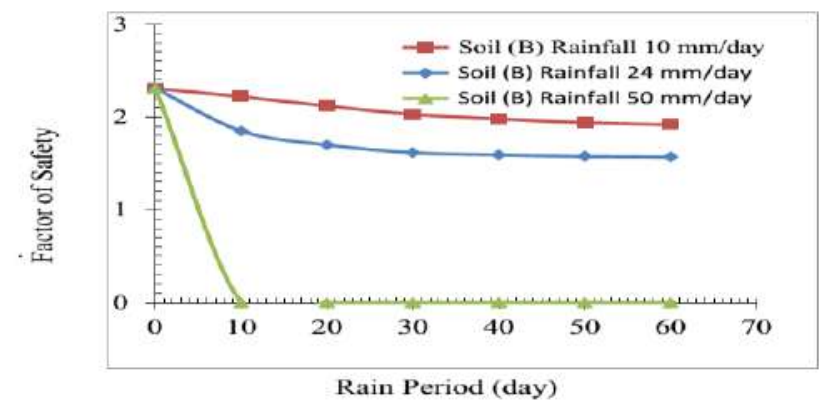

Fig. 10. Factor of safety with rain period for soil (B).
2.2 The effect of applied vertical stresses on the load capacity of the backfills after subjected the rainfall. The load has been applied to the soil slopes (A and B) after the end of the rain period for three cases of rainfall intensity which have been previously mentioned. Figures (11 and 12) show the variations in load settlement curve of the soil slopes (A and B); the results presented in these figures show that the settlement of the backfills increases with the applied vertical stresses, the load capacity decreases with increase in the intensity of rainfall.

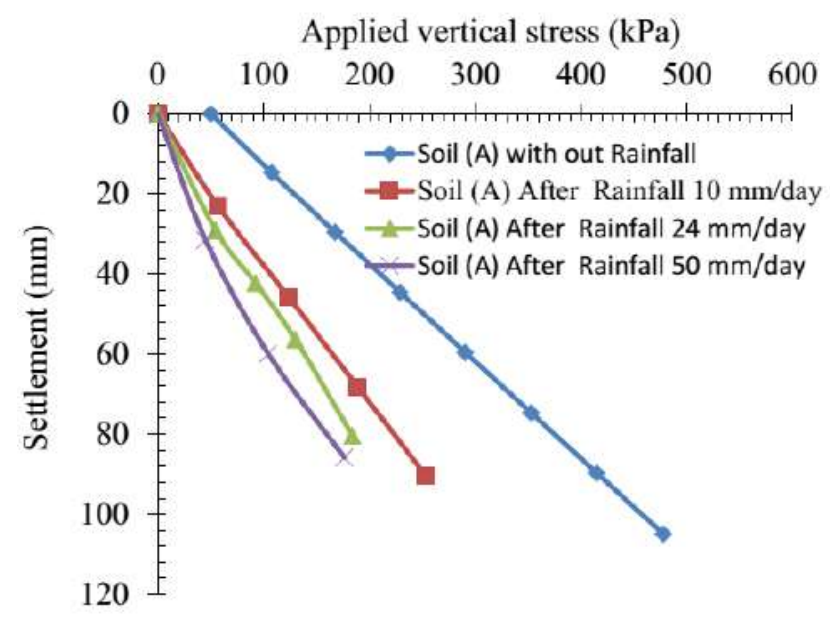

Fig. 11. Stress-settlement characteristics of soil.

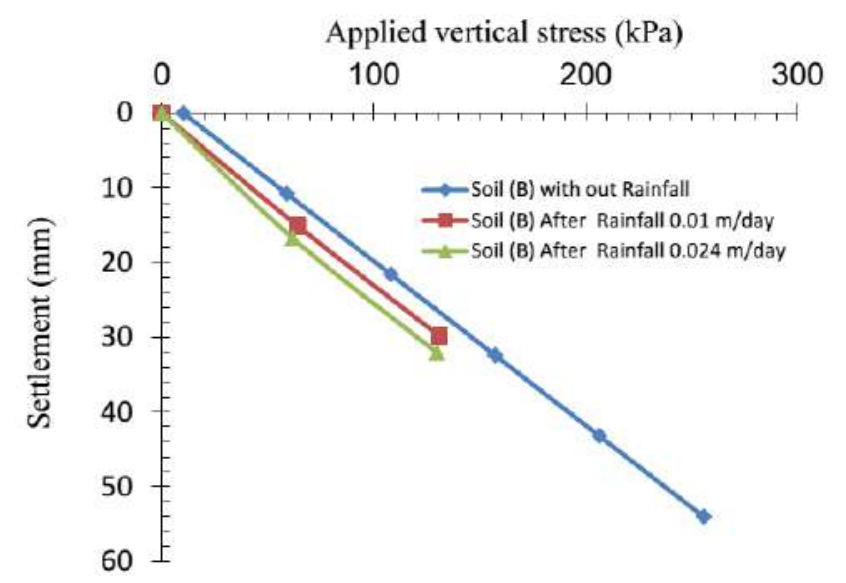

Fig. 12. Stress-settlement characteristics of soil (B) after subjected to rain. 
It is important to indicate that before the rainfall, the load capacity of the soil slopes (A and B) were (400 and $240 \mathrm{kPa}$ ) respectively, after the application of the rainfall, (i.e. after 60 day of rain intensities 10, 24 and 50 $\mathrm{mm} /$ day) the load capacity decreases to a values of (210, 183 and $132 \mathrm{kPa}$ ) for soil slope (A). This gives a reduction in the load capacity of $(47.5,54.25$ and 67$) \%$. On the other hand, for soil B, these values decrease $(110,92$ and 0 $\mathrm{kPa})$, and this gives a reduction in the load capacity of $(54.16,61.6$ and 100$) \%$. This reduction in load capacity is the function of the loss of matric suction and the generation of positive pore water pressure and the loss of friction and cohesion as well. Figures (13 and 14) show the safety factor with the applied load for soil slope (A and B). The factor of safety decreases with the increase of the applied load until it reaches a minimum value (1). It

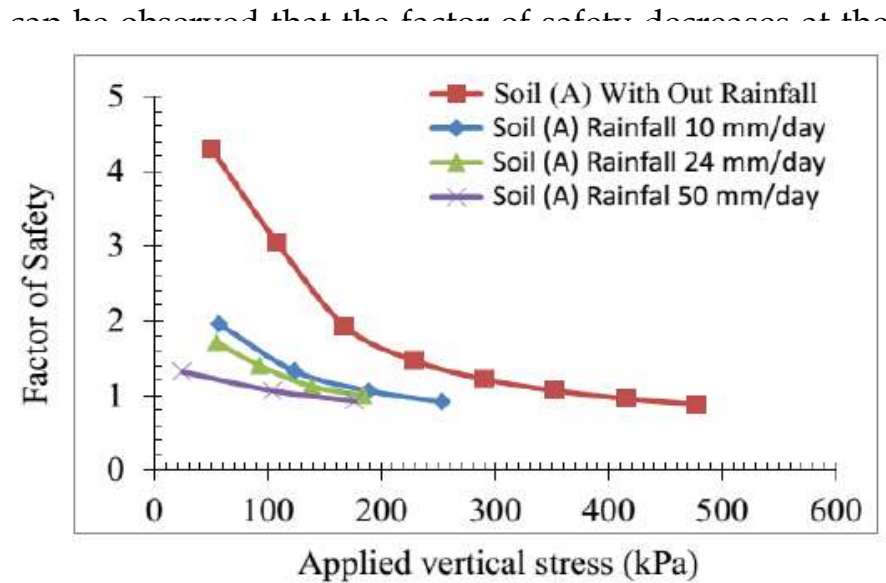

Fig. 13. Factor of safety with applied vertical stress for soil (B) after subjected to rain.

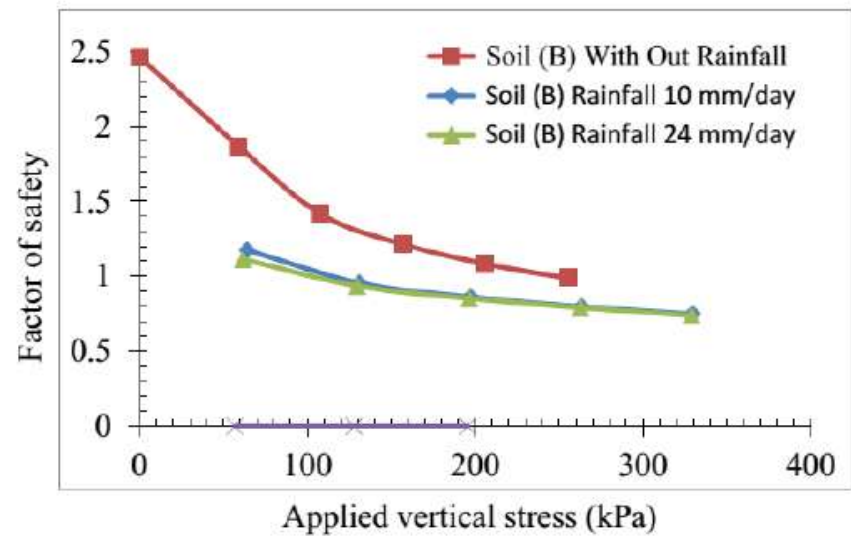

Fig. 14. Factor of safety with applied vertical stress for soil (B) after subjected to rain.
Figure (15) shows the relationship between the pore water pressure values and the applied vertical stresses. It can be added that the pore water decreases with the applied vertical stresses, this can be pointed out by the dissipation of water from the voids and diminish the void sizes.

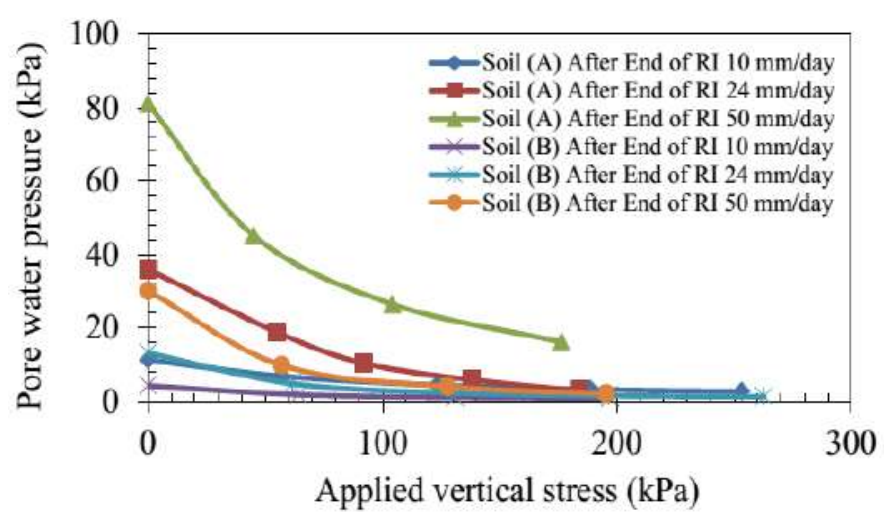

Fig. 15. Change of pore water pressure with applied vertical stress for soil (A and B) after subjected to rain.

\section{EFFECT OF PHREATIC LINE LEVEL ON THE STABILITY OF THE SLOPE.}

The stability of the slope is highly affected as a result of the variation in the phreatic line level which may cause significant changes in volume, shear strength and hydraulic soil properties. Figures (16 and 17) show the stress-settlement curve and the factor of safety with the applied load for the soil slopes. The load capacity of the soil slopes (A and B) is (400 and 240) $\mathrm{kPa}$ respectively when phreatic line level located on $6 \mathrm{~m}$ from the surface, the load capacity decreases to a value of $\{312 \mathrm{kPa}(22 \%)$ and $200 \mathrm{kPa}(16 \%)\}$ for soil slope (A and B) respectively when the phreatic level raises $2 \mathrm{~m}$ (i.e. phreatic line level located on $4 \mathrm{~m}$ from the surface). On the other hand, this value decreases $\{275 \mathrm{kPa}(31 \%)$ and $182 \mathrm{kPa}(24 \%)\}$ for soil slope (A and B) respectively when the phreatic level raises $4 \mathrm{~m}$ (i.e. phreatic line level located on $2 \mathrm{~m}$ from the surface), this value decreases $\{180 \mathrm{kPa}(55 \%)$ and $50 \mathrm{kPa}$ 
(79 \%)\} for soil slope (A and B) respectively when the phreatic level raises $6 \mathrm{~m}$ (i.e. saturated case). It should be noted that the decrease in the load capacity is due to loose of the matric suction that leads to decrease the shear strength of the soil below the mobilized shear strength along the potential slip surface. Whereas the relationship shows little change in the applied stress with phreatic line level $4 \mathrm{~m}$ to $8 \mathrm{~m}$ from surface because of falling head lies beyond the slip surface of the slope. It also shows that the groundwater table near the top surface of soil cause an added settlement if compared to the deeper groundwater table (Kim, et al., 2017). It is worth noting that the safety factor has also been determined with the applied load. When the phreatic level is at the surface, the factor of safety decreases from (2.37 to 1.3) when the applied load increasing from (0 to 113) $\mathrm{kPa}$ for soil slope (A), the factor of safety continuity decreases with the increase of the applied load until it reaches a minimum value (1) at the load $180 \mathrm{kPa}$. While it decreases from (1.15 to 1 ) when the load increases from $(0-50) \mathrm{kPa}$ for soil slopes (B). It can be noticed that the factor of safety increases at the same load when there is falling phreatic line level from surface for the soil slopes (A and B) Figures (18 and 19).

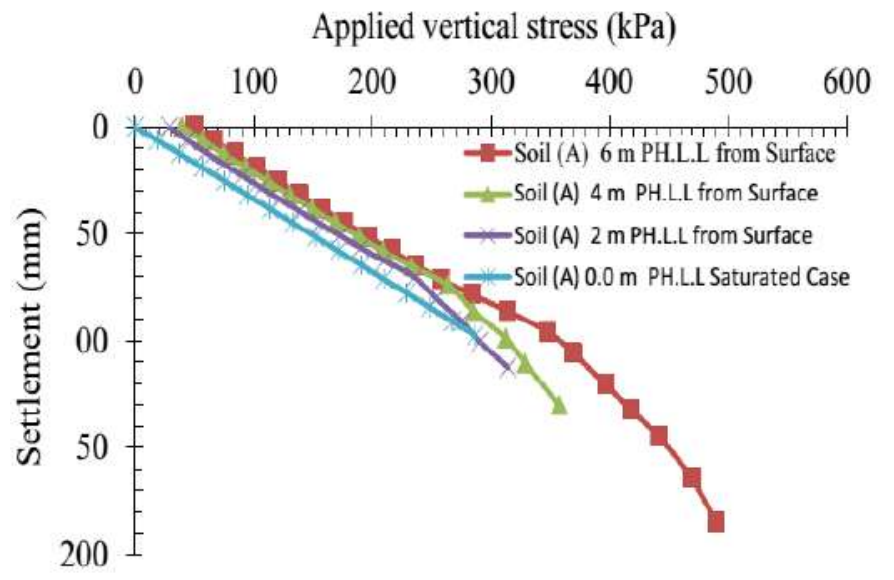

Fig. 16. Stress-settlement characteristics of soil (A) for different PH.L.L.

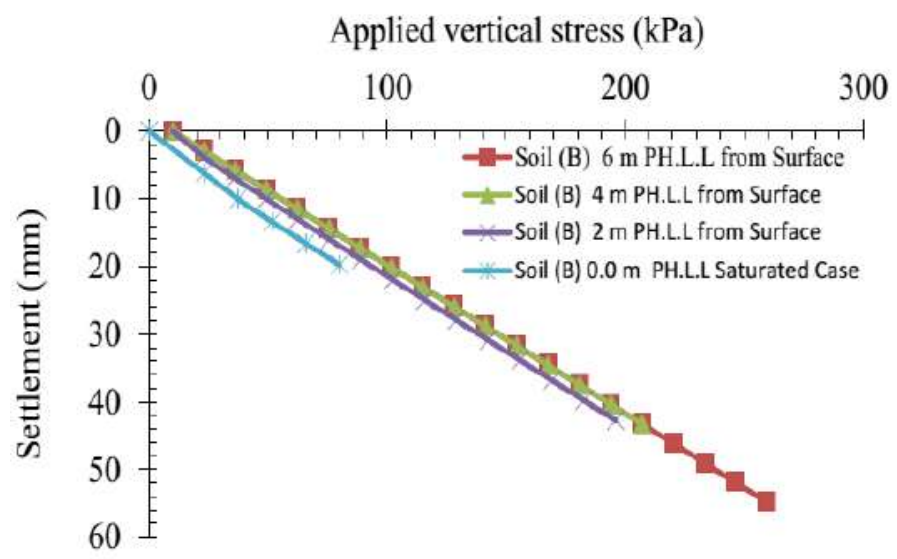

Fig. 17. Stress-settlement characteristics of soil (B) for different PH.L.L

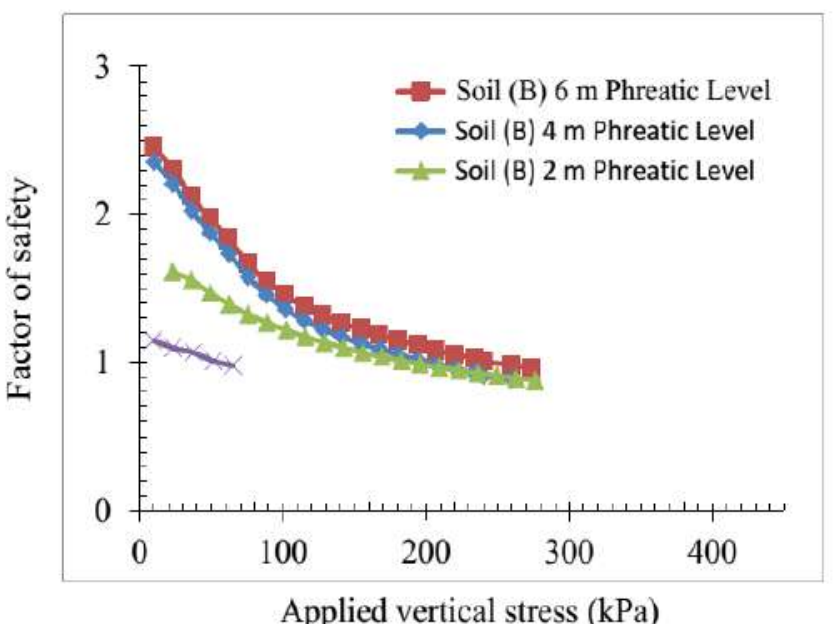

Fig. 18. Factor of safety with applied stress soil (A) for different PH.L.L.

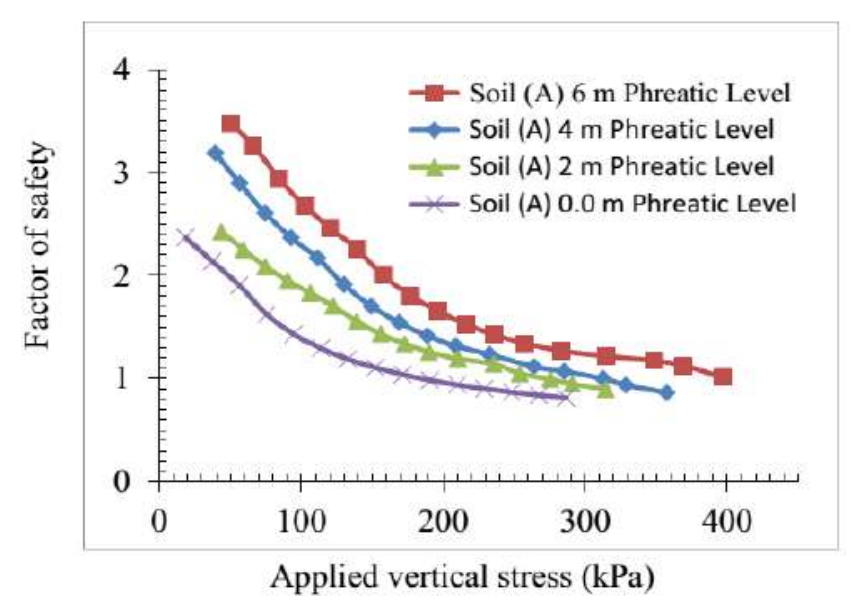

Fig. 19. Factor of safety with applied stress soil (B) for different PH.L.L. 


\section{EFFECT OF SIZE OF FOOTINGS ON THE} STABILITY OF THE SLOPE.

Numerical analysis has been performed to simulate the load-settlement behaviour of the four different width of a rigid footing (1, 2, and 3 ) $\mathrm{m}$ is resting on the unsaturated soil slopes (A and B). The distributed load is applied vertically to the footing without the eccentricity. Figures (20 and 21) shows the geometry and plane strain finite element mesh used in this analysis.

Figures (22 and 23) show the load-settlement responses for different width of footing. For soil slope (A), the load capacity of the largest footing dimension (3m) reaches $345 \mathrm{kPa}$ at $190 \mathrm{~mm}$ settlement, while the

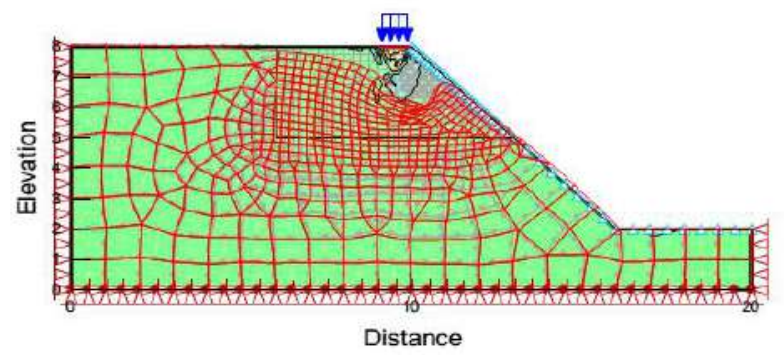

a) Footing width (1) $\mathrm{m}$.

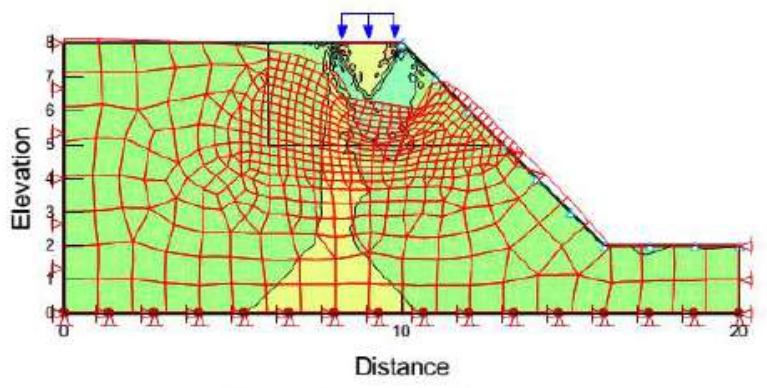

b) Footing width (2) $\mathrm{m}$.

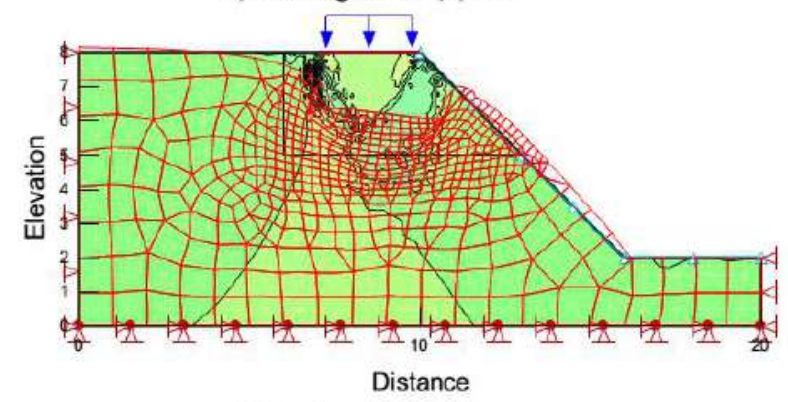

c) Footing width (3) $\mathrm{m}$.

Fig. 20. Geometry and deformed mesh for different footing width of soil (A).

largest footing dimension $(3 \mathrm{~m})$ reaches $194 \mathrm{kPa}$ at
$39 \mathrm{~mm}$ settlement, while the smallest dimension $(1 \mathrm{~m})$ reaches $240 \mathrm{kPa}$ at $76 \mathrm{~mm}$ settlement, which is consistent smallest dimension $(1 \mathrm{~m})$ reaches $412 \mathrm{kPa}(\mathrm{qu})$ at $130 \mathrm{~mm}$ settlement. For soil slope (B), the load capacity of the with the results reached by Briaud and Gibbens (1994); They have already proceed a number round of in-situ square footing (i.e., $1 \mathrm{~m}, 2 \mathrm{~m}, 2.5 \mathrm{~m}$, and $3 \mathrm{~m}$ ) load tests in unsaturated silty sand. They have also noticed that there is an increase in load carrying capacity with decreasing the magnitude of panel and the various settlements uns

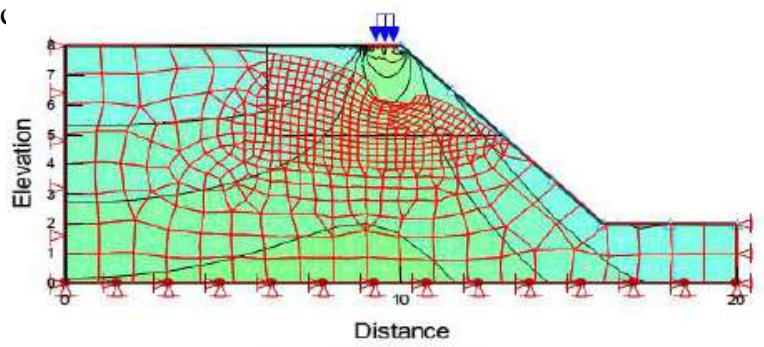

a) Footing width (1) $\mathrm{m}$.

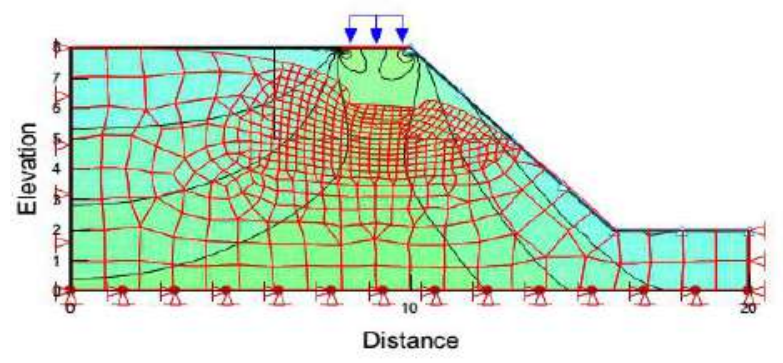

b) Footing width (2) $\mathrm{m}$

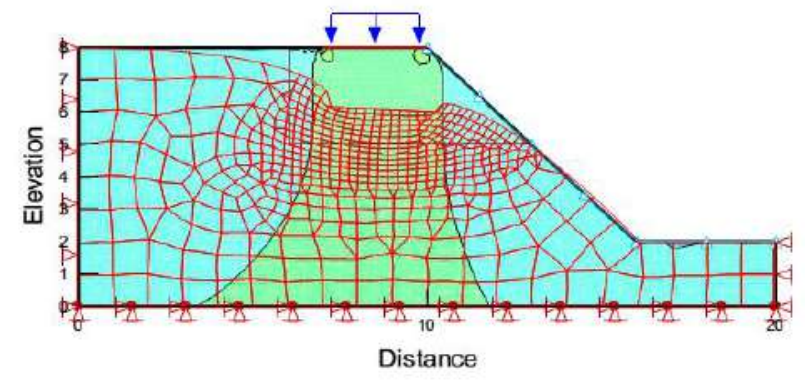

c) Footing width (3) $\mathrm{m}$.

Fig. 21. Geometry and deformed mesh for different footing width of soil (B).

Figures (24 and 25) show the safety factor with the applied load and failure mechanism for soil slope (A and B). For the footing $1 \mathrm{~m}$, the factor of safety decreases with the increase of the applied load until it reaches a 


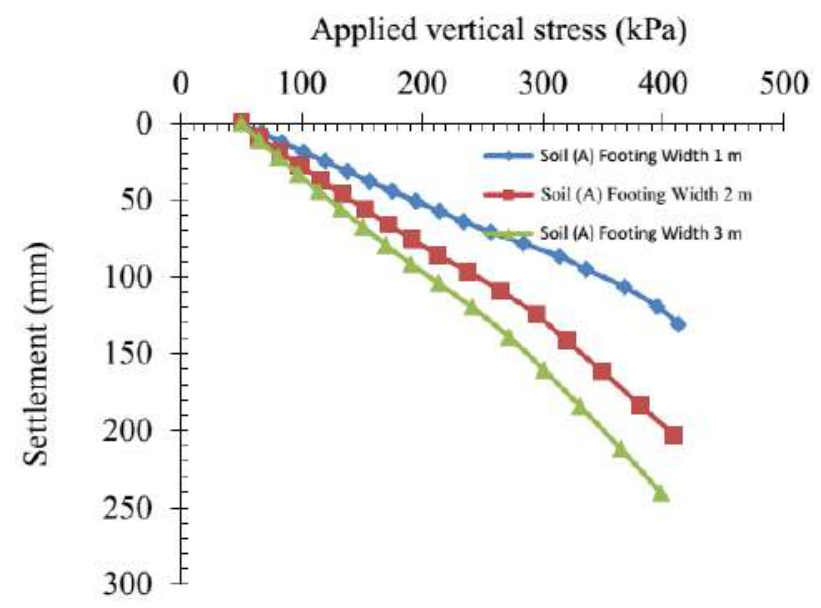

Fig. 22. Stress-settlement characteristics of soil (A) for different footing width

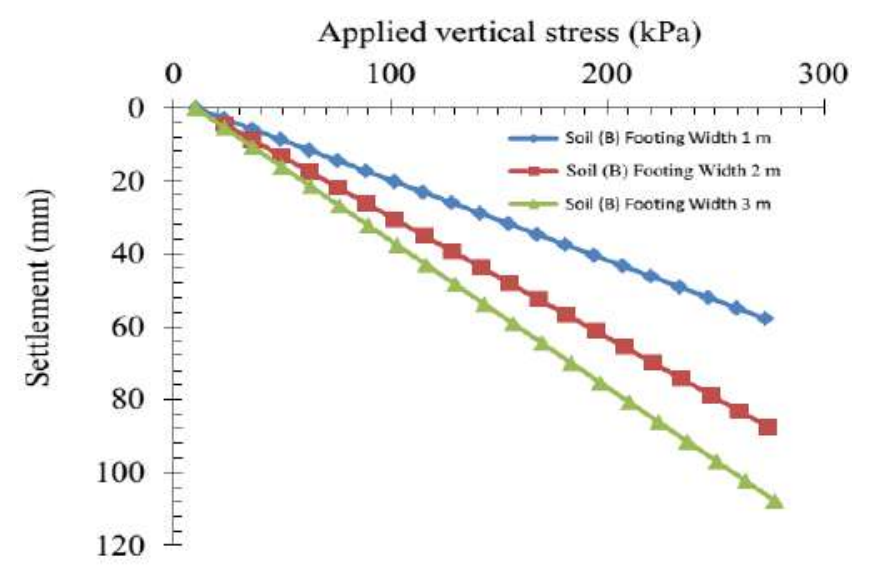

Fig. 23. Stress-settlement characteristics of soil (B) for different footing width.

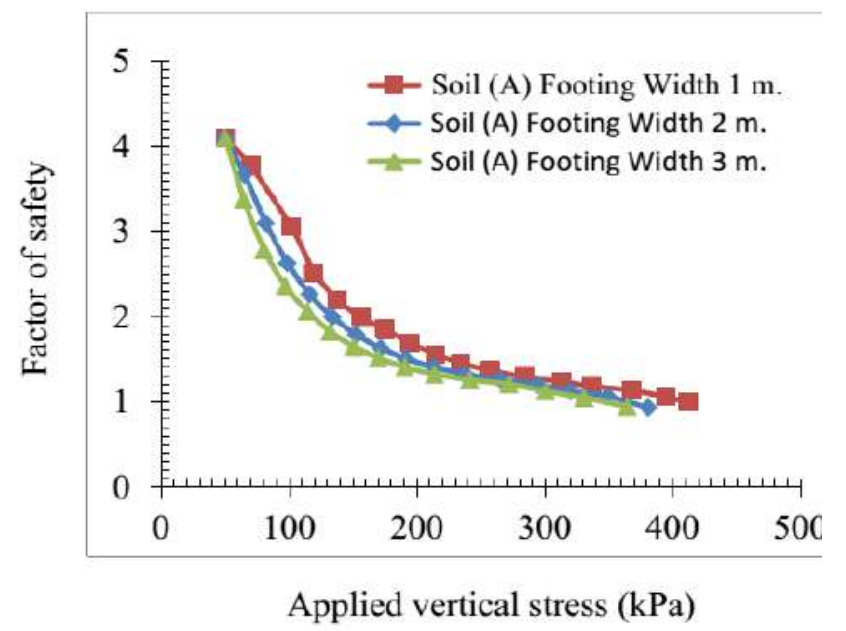

Fig. 24. Factor of safety with applied stress for different footing width of soil (A)

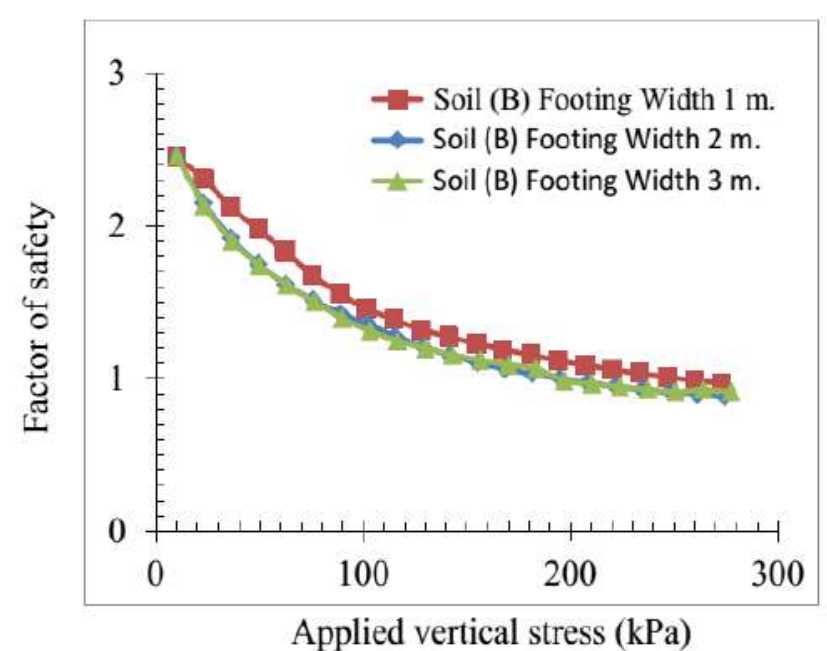

Fig. 25. Factor of safety with applied stress for different footing width of soil (B)

5. EFFECT OF SLOPE ANGLE ON STABILITY OF SLOPE.

The magnitude of the slope steepness is considered as one of the most important factors in determining the ultimate load capacity of a footing built at a crest of the slope. A series of FEM analysis have been conducted to investigate the effect of slope angle $(\beta)$ on the load capacity and stability of the slope (A and B). The analyses have been carried out for $(\beta)$ values of $\left(31^{\circ}, 45^{\circ}\right.$, $63^{\circ}$, and $\left.81^{\circ}\right)$ for the soil slope (A) and $\left(31^{\circ}, 45^{\circ}\right)$ for the soil slope (B).

Figures (26 and 27) show the load-settlement curve for different slope angles. For soil (A) the load capacity, is $(575,412,335$ and $171 \mathrm{kPa})$ for the slope angle $\left(31^{\circ}\right.$, $45^{\circ}, 63^{\circ}$, and $81^{\circ}$ ), while the load capacity is (351 and 240 $\mathrm{kPa})$ for the slope angle $\left(31^{\circ}\right.$ and $\left.45^{\circ}\right)$ for soil (B). Out of this result, it can be noticed that, when the slope angle decreases from $\left(45^{\circ}\right.$ and $\left.31^{\circ}\right)$ the load capacity increases (37 and 46)\% for soil slopes (A and B) respectively. The load capacity decreases (58) \% when the slope angle increases from $\left(45^{\circ}\right.$ to $\left.81^{\circ}\right)$. An agreement to (Ahmadi and Asakereh, 2015; Lyle, 2009) can be easily noticed; when the slope angle increases the ultimate bearing capacity decreases. For slope angles less than 45 degrees, 
there is an increase in bearing capacity due to surcharge loading, whereas there is no increase or decrease between 45 and 63 degrees. There is quite a reasonable decrease in bearing capacity due to surcharge loading for slopes greater than 63 degrees.

Figures (28 and 29) shows the relationship between the safety factors with the applied load for all case of the slope angle. The factor of safety decreases at the same load when the slope angle increases.

According to these figures, it can be said that slope stability decreases with the increase of the slope angle, and thus the tendency of the soil beneath the foundation to move to the slope increases, therefore, failure takes place because of the slope instability and reduces the bearing capacity (Ahmadi and Asakereh, 2015).

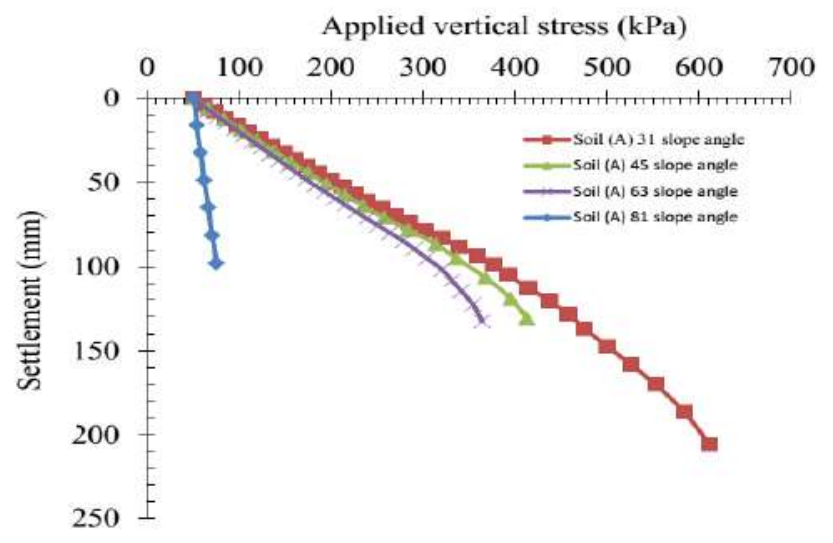

Fig. 26. Stress-settlement characteristics of soil (A) for different slope angle.

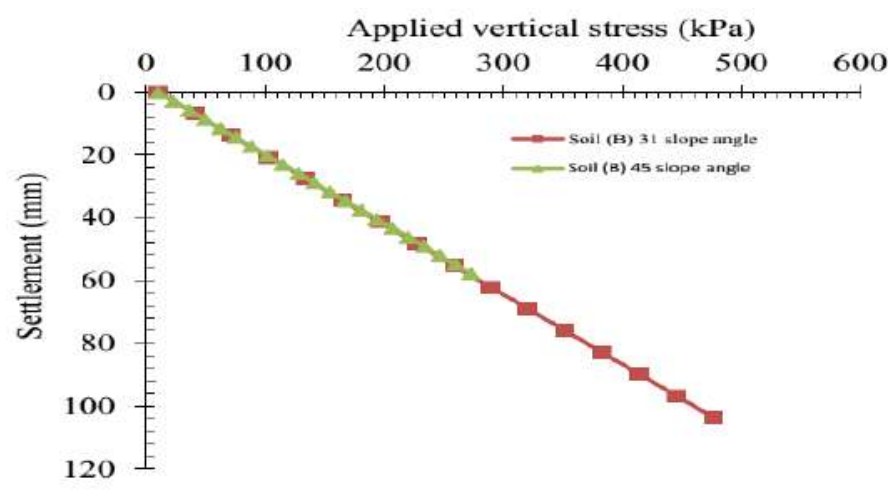

Fig. 27. Stress-settlement characteristics of soil (B) for different slope angle.

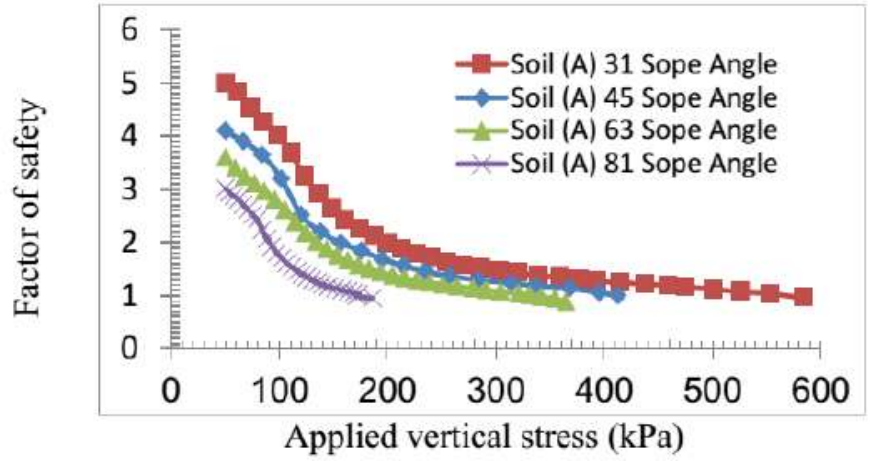

Fig. 28. Factor of safety with applied stress for different slope angle of soil (B)

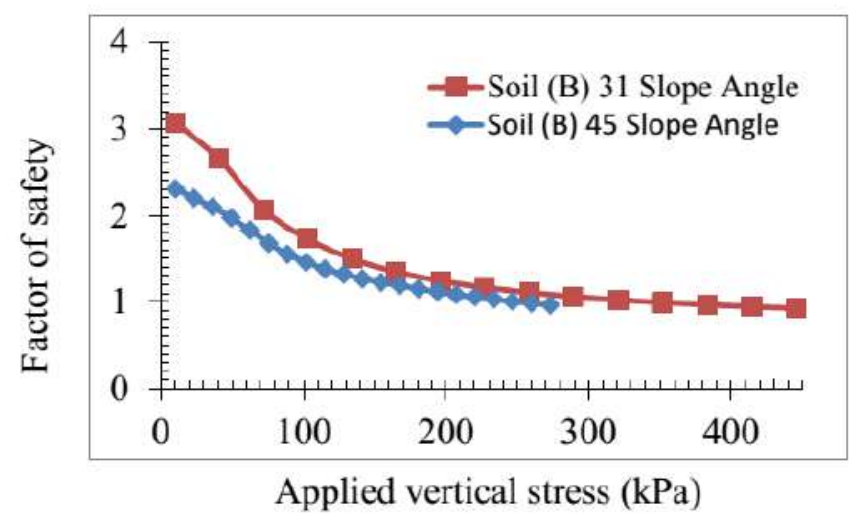

Fig. 29. Factor of safety with applied stress for different slope angle of soil (B)

\section{DESIGN CHARTS ACCORDING TO PARAMETRIC STUDY FOR FOOTINGS SET ON CREST OF A SLOPE.}

Numerical model based on the finite element analysis (Geo slope) program which uses for the development of a design chart for the footing built on a (clay and silt) soil slopes. These charts are suggested to represent the variation of load capacity with the angle of slope for different variables including the footing width and phreatic line level. The influence of each of these parameters will be presented further below.

Out of the results, the design charts are divided into five groups according to the location of the phreatic line level from the surface:

1. Phreatic line level on surface.

2. Phreatic line level $2 \mathrm{~m}$ below the surface. 
3. Phreatic line level $4 \mathrm{~m}$ below the surface.

4. Phreatic line level $6 \mathrm{~m}$ below the surface.

5. Phreatic line level $8 \mathrm{~m}$ below the surface.

Figure (30) shows the relationship between the load capacity and the angle of slope for various footing width. It can be mentioned that, the load capacities of footing decreases with the steepness of the slope and the width of the footing. Concerning the clay soil slope with footing width (1) $\mathrm{m}$, the reduction in load capacity is (10) \% when the slope angle increases from $\left(31^{\circ}\right.$ to $\left.45^{\circ}\right)$, this reduction in load capacity becomes (22 and 49) \% when the slope angle increases to $\left(63^{\circ}\right.$ and $\left.81^{\circ}\right)$. The same figure also shows a reduction in the load capacity with the increase of footing width to some extent. This reduction becomes smaller when it reaches the foot width of $3 \mathrm{~m}$. For silt soil slope, when the slope angle increases from $\left(31^{\circ}\right.$ to $\left.45^{\circ}\right)$, the reduction in load capacity is $(31,43$, and 45$) \%$ for footing widths of $(1,2$ and 3$)$ respectively.

As for Figures (31 to 34), they show an increase in the load capacity whenever the water table drops down. Adding that these drops lead to an increase in the matric suction and therefore, it increases the shear resistance and hence, the load capacity under the footing increases. According to these results; for slope angle $\left(31^{\circ}\right)$ and footing width $1 \mathrm{~m}$, the amount of increase in the load capacity is $(18,48,79$, and 112$) \%$ when the water table drops to $(2,4,6$ and 8$)$ from the surface respectively for soil (A). As for soil (B), the amount of increase in the load capacity is $(36,57,84$, and 110$) \%$ when the water table drops to $(2,4,6$ and 8$)$ from the surface respectively. This increase in load capacity will be reduced with the increase of footing width and decrease with increase slope angle.

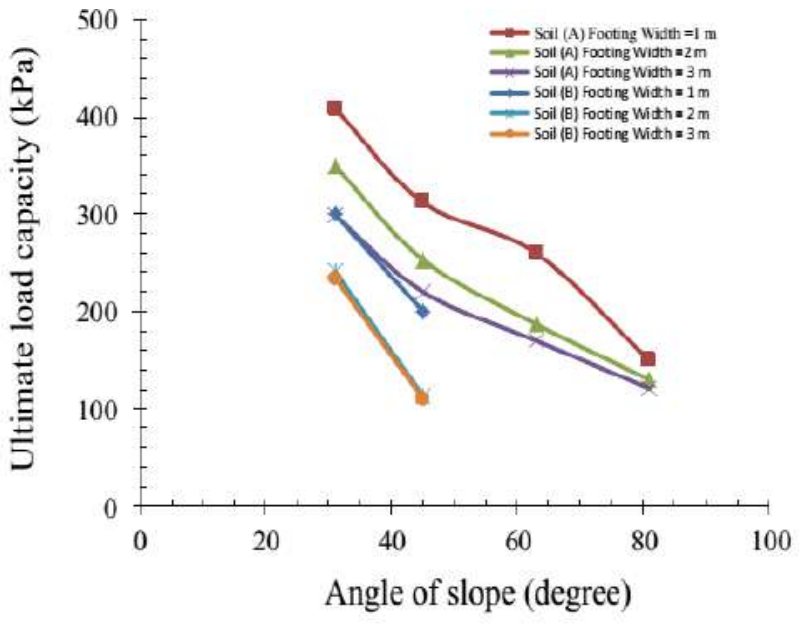

Fig. 30. Chart 1 for estimating load capacity for phreatic line level on surface.

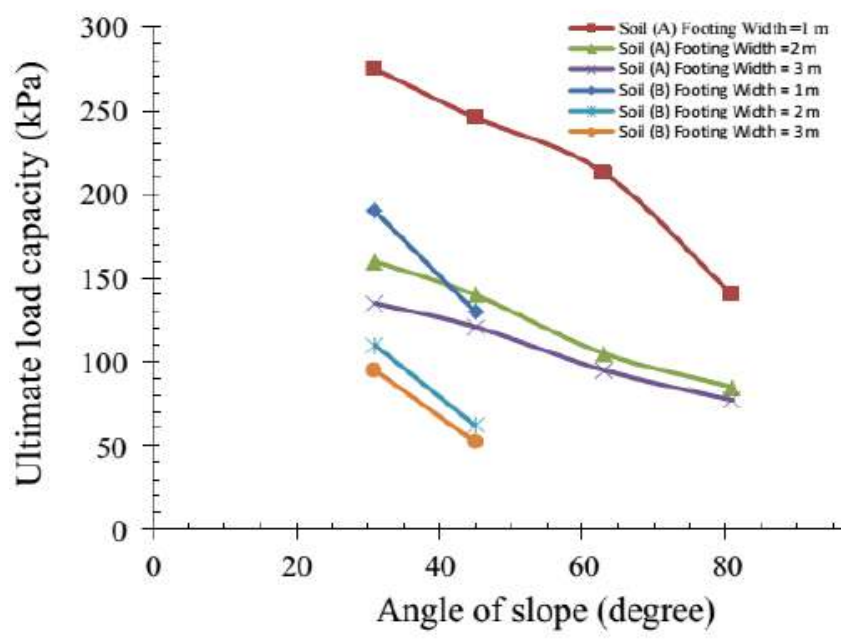

Fig. 31. Chart 2 for estimating load capacity for phreatic line level $2 \mathrm{~m}$ below the surface.

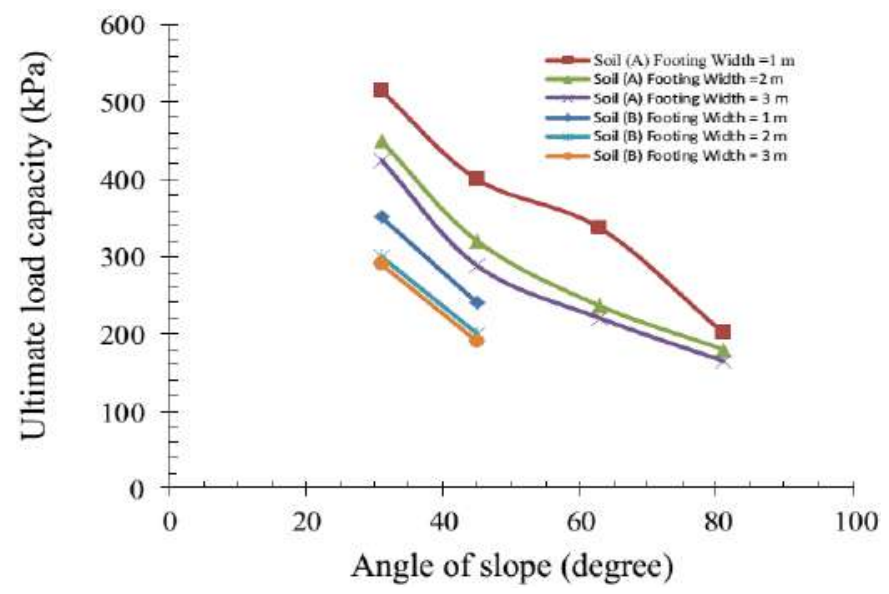

Fig. 32. Chart 3 for estimating load capacity for phreatic line level $4 \mathrm{~m}$ below the surface. 


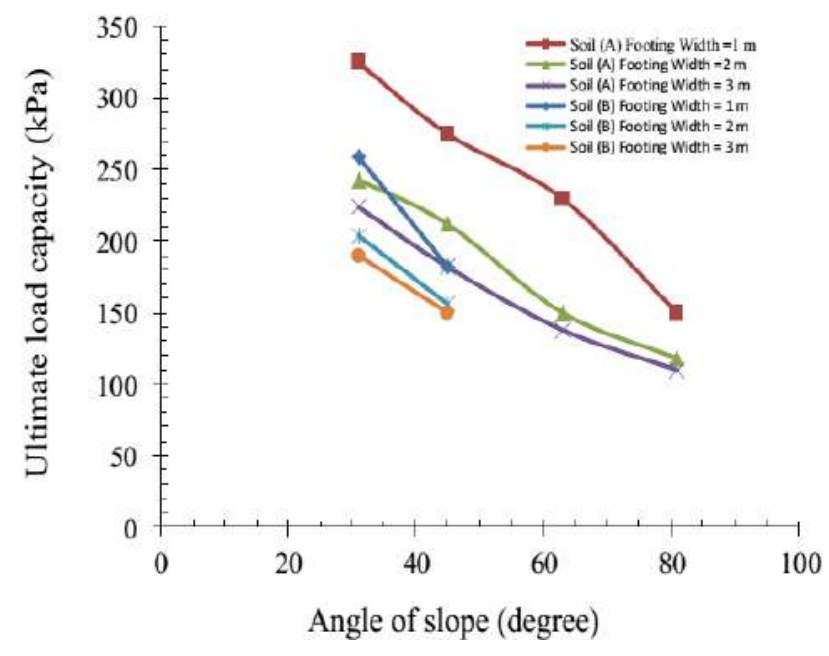

Fig. 33. Chart 4 for estimating load capacity for phreatic

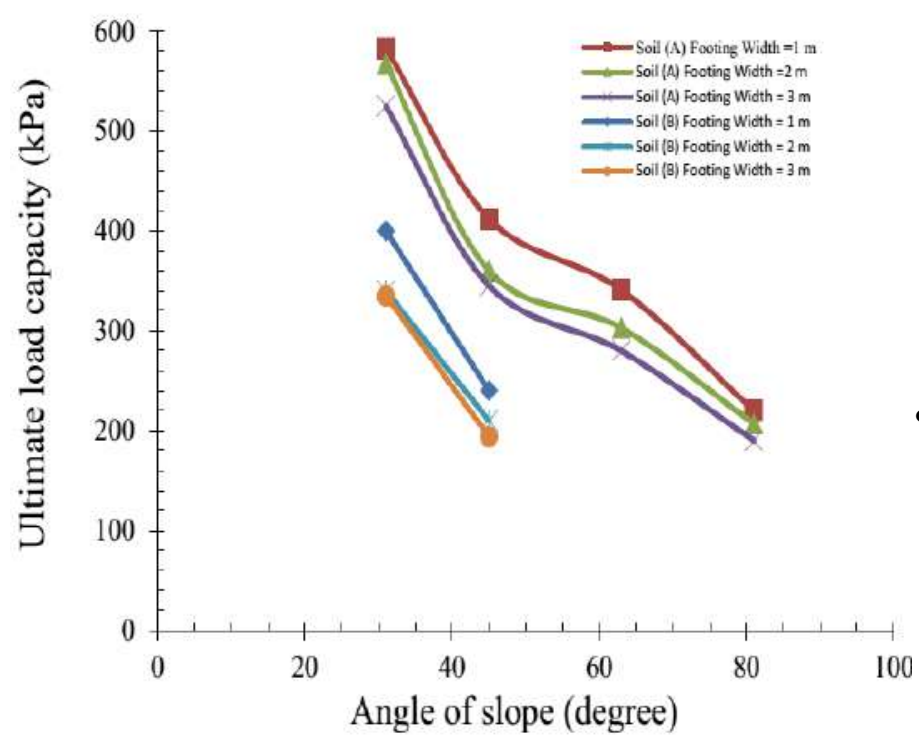

Fig. 34. Chart 5 for estimating load capacity for phreatic line level $8 \mathrm{~m}$ below the surface.

\section{CONCLUSIONS.}

- The rainfall governs the suction value in soil, intensity, rainfall duration and the saturated permeability of the soil. The soil (B) is very sensitive to the changes in the pore pressure if it is compared with soil (A). For soil slope (A), the pore pressure has been changed from (-50) $\mathrm{kPa}$ to $(11.3,15.9$ and 81) $\mathrm{kPa}$ for intensity (10, 24 and 50) $\mathrm{mm} /$ day respectively. As for soil (B), the pore pressure has been changed from (-10) $\mathrm{kPa}$ to $(4.3,13.2$ and 30.1)
$\mathrm{kPa}$ for intensity (10, 24 and 50) $\mathrm{mm} /$ day respectively.

- Out of the parametric study results, it is possible to form design charts between the ultimate bearing capacity, slope angle, footing width and phreatic line level. The relation indicates the clay soil slope with footing width (1) $\mathrm{m}$, the reduction in load capacity is (10) \% when the slope angle increases from $\left(31^{\circ}\right.$ to $45^{\circ}$ ), this reduction in load capacity becomes (22 and $49) \%$ when the slope angle increases to $\left(63^{\circ}\right.$ and $\left.81^{\circ}\right)$

- The reduction in the load capacity increase with increasing footing width to some extent. This reduction becomes smaller when it reaches the foot width of $3 \mathrm{~m}$. For soil slope (B), when the slope angle increases from $\left(31^{\circ}\right.$ to $\left.45^{\circ}\right)$, the reduction in load capacity is $(31,43$, and 45$) \%$ for footing widths of $(1$, 2 and 3) respectively

- An increase in the ultimate bearing capacity whenever the phreatic line level dropped down has been obviously shown by the results.

\section{REFERENCES}

1. Ahmadi, M.H., Asakereh, A., (2015), "Numerical Analysis of the Bearing Capacity of Strip Footing Adjacent to Slope", International Journal of Science and Engineering Investigations. Vol. 4, No. 46, pp. 49-53.

2. Briaud, J.L. and Gibbens, R. (1994), "Predicted and measured behavior of five large spread footings on sand", in Proc. Prediction Symp. ASCE GSP41.

3. Chen, H., Lee, C.F., Law, K.T., 2004. Causative mechanism of rainfall-induced fill slope failures. Journal of Geotechnical and Geo-environmental Engineering, ASCE, 130, (6), 593-602. 
4. Fredlund, D.G., Rahardjo, H., 1993. Soil Mechanics for Unsaturated Soils. ohn Wiley and Sons, Inc., USA

5. Kassim A, Gofar N, Lee M. L, Rahardjo H. (2012). Modeling of suction distributions in an unsaturated heterogeneous residual soil slope. Engineering Geology, 131-132: 70-82.

6. Lee M. L, Kassim A, Gofar N. 2011 Performances of two instrumented laboratory models for the study of rainfall infiltration into unsaturated soils. Engineering Geology, 117, 78-89.

7. Liu, G. R. and Quek, S. S., (2003), "The Finite Element Method", A Practical Course, Department of Mechanical Engineering, National University of Singapore.

8. Lyle, N. R., (2009), "Comprehensive Design Charts for the Footing on Slope Problem", University of Southern Queensland Faculty of
Engineering and Surveying, Courses ENG4111 and ENG4112 Research Project.

9. Stormont, J.C., Anderson, C.E., 1999. Capillary barrier effect from underlying coarser soil layer. Journal of Geotechnical and Geoenvironmental Engineering, ASCE, 125 (8), 641648.

10. Travis, Q.B., Houston, S.L., Marinho, F.A.M., Schmeeckle, M., 2010. Unsaturated infinite slope stability considering surface flux. Journal of Geotechnical and Geo-environmental Engineering, ASCE, Vol. 136, No. 7, pp. 963974.

11. Zou, Z.Y., Young, M.H., Wierenga, P.J., (2001), "Estimation of depth averaged unsaturated soil hydraulic properties from infiltration experiments", Journal of Hydrology, Vol. 242, No. (1-2), pp. 26-42. 